\title{
Heat removal analysis on steel billets and slabs produced by continuous casting using numerical simulation
}

\author{
A. Ramírez-López ${ }^{1,2}$ (1D • D. Muñoz-Negrón ${ }^{1}$ M. Palomar-Pardavé ${ }^{2}$. \\ M. A. Romero-Romo ${ }^{2}$ - J. Gonzalez-Trejo ${ }^{2}$
}

Received: 21 September 2016 / Accepted: 11 May 2017 / Published online: 17 June 2017

(C) The Author(s) 2017. This article is an open access publication

\begin{abstract}
Simulation of a continuous casting process (CCP) is very important for improving industrial practices, reducing working times, and assuring safety operating conditions. The present work is focused on the development of a computational simulator to calculate and analyze heat removal during continuous casting of steel; routines for reading the geometrical configuration and operating conditions were developed for an easy management. Here, a finite difference method is used to solve the steel thermal behavior using a $2 \mathrm{D}$ computational array. Conduction, radiation, and forced convection equations are solved to simulate heat removal according to a steel position along the continuous casting machine. A graphical user interface (GUI) was also developed to display virtual sketches of the casting machines; moreover, computational facilities were programmed to show results such as temperature and solidification profiles. The results are analyzed and validated by comparison with industrial trials; finally, the influence of some industrial parameters such as casting speed and quenching conditions is analyzed to provide some recommendations in order to warrant safety operating conditions.
\end{abstract}

Keywords Continuous casting · Steel manufacturing $\cdot$ Heat removal $\cdot$ Thermal behavior $\cdot$ Computer simulation . Computational algorithms

A. Ramírez-López

adan.ramirez@itam.mx; adaralo@starmedia.com

1 Academic Department of Industrial Engineering, Instituto Tecnológico Autónomo de México (ITAM), 01080 Mexico city, Mexico

2 Department of Materials Science, Universidad Autónoma Metropolitana (UAM Azcapotzalco), 02200 Mexico city, Mexico

\section{Nomenclature}

$k \quad$ Thermal conductivity $\left(\mathrm{W} /\left(\mathrm{m}{ }^{\circ} \mathrm{C}\right)\right)$

$c_{\mathrm{p}} \quad$ Heat capacity at constant pressure $\left(\mathrm{J} /\left(\mathrm{Kg}{ }^{\circ} \mathrm{C}\right)\right)$

$q \quad$ Heat flux (J)

$\mathrm{T}_{\text {Liq }} \quad$ Temperature of liquidus in the $\mathrm{Fe}-\mathrm{C}$ phase diagram $\left({ }^{\circ} \mathrm{C}\right)$

$T_{\text {Sol }} \quad$ Temperature of solidus in the Fe-C phase diagram $\left({ }^{\circ} \mathrm{C}\right)$

$T_{\mathrm{AR} 1} \quad$ Temperature for phase transformation in the Fe-C phase diagram $\left({ }^{\circ} \mathrm{C}\right)$

$T_{\mathrm{AR} 3} \quad$ Temperature for phase transformation in the Fe-C phase diagram $\left({ }^{\circ} \mathrm{C}\right)$

Pr Prandtl number (Dimensionless)

$\mathrm{Nu} \quad$ Nusselt number (Dimensionless)

Re Reynolds number (Dimensionless)

$H \quad$ Enthalpy (KJ)

$h \quad$ Heat transfer coefficient (removal) $\left(\mathrm{J} /\left(\mathrm{m}^{2} \mathrm{~s}^{\circ} \mathrm{C}\right)\right)$

$\alpha \quad$ thermal diffusivity $\left(\mathrm{m}^{2} / \mathrm{s}\right)$

$\Delta x \quad$ Element size for discretization of the steel (axis $x$ ) (mm)

$\Delta y \quad$ Element size for discretization of the steel (axis $y$ ) (mm)

$\Delta z \quad$ Element size for discretization of the steel (axis $z$ on casting direction) ( $\mathrm{mm}$ )

$\Delta t \quad$ Step time for the simulation (s)

$r_{\mathrm{c}}$

$l_{\text {mold }}$

SCS

$\theta$

radius of the curved zone $(\mathrm{m})$

mold length (m)

Secondary cooling system

Angle of an indicated spray segment in the SCS

$\left(\left(^{\circ}\right)\right.$ angular $)$

$\begin{array}{ll}\rho & \text { density }\left(\mathrm{Kg} / \mathrm{m}^{3}\right) \\ \Omega & \text { Shooting angle (referred for each spray) }\left(\left(^{\circ}\right)\right.\end{array}$ angular)

$\varepsilon_{\text {steel }} \quad$ Steel emissivity (effectiveness in emitting energy; goes from 0 to 1 , assumed as 0.6 ) (Dimensionless) 


$\begin{array}{lll}\sigma & \text { Stephan-Boltzmann constant }\left(5.67 \times 10^{-8}\right) & \mathrm{Nu}_{\mathrm{ns}, \text { side }} \\ & \left(\mathrm{W} / \mathrm{m}^{2} \mathrm{~K}^{4}\right) & h_{\mathrm{ns}, \text { side }} \\ v_{\mathrm{s}} & \text { Casting speed (referred for each strand) }(\mathrm{m} / \mathrm{min}) & q_{\mathrm{ns}, \text { side }} \\ V_{\mathrm{w}} & \text { Water flow rate }(\mathrm{l} / \mathrm{min}) & T_{\mathrm{I}, \mathrm{J}} \\ \mathrm{I} & \text { Subindexes used to indicate position in the } & T_{\mathrm{amb}} \\ & \text { discretized steel (Subindexes) } & T_{\mathrm{W}} \\ \mathrm{J} & \text { Subindexes used to indicate position in the } & \mathrm{dr}_{\mathrm{s}}^{\mathrm{t}} \\ & \text { discretized steel (Subindexes) } & H_{\mathrm{I}, \mathrm{J}}^{\mathrm{t}} \\ t_{\mathrm{o}} & \text { Strands opening time (s) } & \\ t_{\mathrm{c}} & \text { Strands closing time (s) } & T_{\mathrm{max}} \\ \mathrm{ns}_{\mathrm{t}} & \text { Number of segments in the SCS (Numeric) } & \\ \mathrm{nsp}_{\mathrm{ns}} & \text { Number of sprays per segment (Numeric) } & T_{\mathrm{min}} \\ l_{\mathrm{free}} & \text { Length of the free zone (m) } & \\ d & \text { Diameter of the nozzle (mm) } & \\ d_{\mathrm{bi} \text {-nozzle }} & \text { Distance from the nozzle to the section surface } & \end{array}$

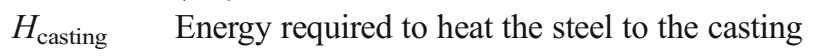
temperature $(\mathrm{J})$

$H_{\mathrm{I}, \mathrm{J}} \quad$ Energy required to heat the steel to the casting temperature at the nodal positions I and $\mathrm{J}(\mathrm{J})$

W Element weight $(\mathrm{kg})$

lx Section dimension for in the $\mathrm{x}$ direction $(\mathrm{mm})$

ly Section dimension for in the y direction ( $\mathrm{mm}$ )

$\mathrm{nI} \quad$ Discretization node in position I (Numeric)

$\mathrm{nJ} \quad$ Discretization node in position $\mathrm{J}$ (Numeric)

$v_{\text {strand }} \quad$ Casting speed on the strand $(\mathrm{m} / \mathrm{min})$

$T_{\text {casting }} \quad$ Casting temperature $\left({ }^{\circ} \mathrm{C}\right)$

$q_{\text {side }} \quad$ Heat flux removed (J)

Ao Constant (Constant)

Bo Constant (Constant)

$t_{\mathrm{dwell}} \quad$ Time of the steel remaining in the mold (s)

$l_{\mathrm{c}} \quad$ Length of the curved zone (m)

$l_{\text {tot }} \quad$ Total length (m)

$l_{\mathrm{SCS}} \quad$ Secondary cooling system length (m)

$l_{\text {free-curved }}$ Free zone length on the curved zone (m)

$l_{\text {free }} \quad$ Length of the final straight section where the section is driven out $(\mathrm{m})$

$l_{\mathrm{m}} \quad$ Distance measured from the meniscus level (m)

$l_{\mathrm{ns}} \quad$ Length of each segment $(\mathrm{m})$

$\theta_{\text {spray }} \quad$ Angular distance between the sprays $\left(\left(^{\circ}\right)\right.$ angular)

$\theta_{\mathrm{ns}} \quad$ Angular distance of a segment in the SCS $\left(\left(^{\circ}\right)\right.$ angular)

$\theta_{\text {ns-1 }} \quad$ Angular distance of the previous segment in the SCS $\left(\left(^{\circ}\right)\right.$ angular $)$

nsp Number of sprays in the segment (Numeric)

$\mathrm{d}_{\mathrm{w} \text { ns,side }} \quad$ Distance from the nozzle to billet surface $(\mathrm{cm})$

$v_{\mathrm{w} \text { ns,side }}$ Speed of the water in contact with the section surface $(\mathrm{m} / \mathrm{s})$

$v_{\text {nozzle }} \quad$ Speed of the water in the nozzle $(\mathrm{m} / \mathrm{s})$

$A_{\text {nozzle }} \quad$ Area of the nozzle $\left(\mathrm{mm}^{2}\right)$

$A_{\mathrm{w}} \quad$ Sprayed area $\left(\mathrm{mm}^{2}\right)$

$\Omega_{\mathrm{ns} \text {,side }} \quad$ Shooting angle of the spray $\left(\left(^{\circ}\right)\right.$ angular $)$

$\mu$
Nusselt number (Dimensionless)

Heat removal coefficient

Heat removal in a segment in a specific side $(\mathrm{J})$

Temperature en in the node of position $(\mathrm{I}, \mathrm{J})\left(\left({ }^{\circ} \mathrm{C}\right)\right)$

Environmental temperature $\left(\left({ }^{\circ} \mathrm{C}\right)\right)$

Water temperature $\left(\left({ }^{\circ} \mathrm{C}\right)\right)$

Displacement of the control volume (m)

Updated enthalpy in the node of position (I, J) for

the instance $(\mathrm{t})$ during the simulation $(\mathrm{J})$

Temperature maximum (used to display values)

$\left(\left({ }^{\circ} \mathrm{C}\right)\right)$

Temperature minimum (used to display values)

$\left(\left({ }^{\circ} \mathrm{C}\right)\right)$

\section{Introduction}

The continuous casting process $(\mathrm{CCP})$ is the most popular method to produce big volumes of steel in commercial sections (billets, blooms, and slabs) without interruption. These sections are primary products that are commonly post-manufactured by rolling or forging methods to obtain more specific steel products to be used in the building, automotive, metal-mechanic, and other manufacturing industries. Electric arc furnaces are used to foundry steel scrap, which is initially transported into a ladle for refining. Subsequently, steel is cast in tundishes to be distributed towards the strands; then the liquid steel is cast in the molds. Here, the steel adopts the shape of the sections to be produced.

The understanding of heat removal phenomena during CCP is very important for casters and steel industries. The influence of the geometrical configuration and the operating conditions of the continuous casting machine (CCM) must be known to guarantee safety operating conditions and good productivity and quality. Computational simulation has become a useful tool to simulate industrial processes because it is a lowcost method that avoids physical experimentation and moreover allows the inclusion of critical operating conditions without any risk. Early research works about the of CCP [1-6] were based on models with oversimplified equations for approaching and describing heat removal, due to limited computer capacities. Nowadays, a conventional desktop PC or a laptop can make millions of logical and numerical operations in only a few seconds. The increment on data management and processing added to the improvement on safety and storage data capacities has made possible to solve complex problems. In this way, software improvement and numerical methods have allowed the development of more sophisticated models, more friendly environments for the users, and more efficient computer algorithms. 
Previous models [1-6] considered the discretization of the steel using a 2D approach, simulating only one-fourth of the steel billets and assuming identical heat removal conditions. The number of nodes used to represent the steel was limited, computing time was also expensive, and results might be printed or saved to be plotted or displayed with a post-treatment. These were the initial efforts to use computers for predicting steel thermal behavior using only elementary data and basic simplified numerical methods; although, these models gave good approaches to calculate heat fluxes inside the steel sections. It was necessary to solve more complicated systems for the steel sections due to the different mechanisms involved, such as forced convection and radiation.

Other authors [7-12] continued developing more sophisticated models. Blase et al. [13] simulated the heat transfer for wires and sections produced by continuous casting. In these cases, the problem can be simplified using 2D or 1D models due to their round geometry and the application of the symmetrical heat removal conditions. Furthermore, other researchers [10-12] developed equations for describing heat removal on the primary cooling system (the mold) and on the secondary cooling systems (SCS) formed of segments with sprays. Nonetheless, it is complicated to simulate heat removal along the entire process due to different conditions prevailing everywhere in the CCM. Complex coefficients must be defined in the mold, and specific conditions under sprayed and non-sprayed areas must also be established. Therefore, in this work, a finite difference method was used to solve the steel thermal behavior using a $2 \mathrm{D}$ computational array; here, conduction, radiation, and forced convection equations were included to calculate the heat removal at every specified steel position along the CCM. Appropriate computational tools for reading data and simulating the industrial process were developed to obtain good approaches quickly and be capable to represent graphically the results of the simulations, rather than straight the usage of simulation software, which requires training and a specific data management, coupled with the requirement on storage data capacities that must be satisfied. Moreover, the physical and chemical influence of the variables involved can be easily identified. In addition, efficient calculation routines which avoid unnecessary operations provide a competitive advantage.

\section{Reading data}

Reading data is the first step to simulate an industrial process. Here, computational facilities were programmed to be included in the numerical simulator with appropriate warnings to avoid errors during declaring. Then the user must input the information in the following blocks:

- The section to be cast
- The steel chemical composition

- The geometrical configuration of the CCM

- The operating conditions

The user must select the steel section to be cast: billets, blooms, or slabs. These are the most frequently sections produced by CCP. Then the dimensions of the section and the nodes used for discretization are read. The steel chemical composition is subsequently defined. Here, the mass percent of each element in the steel is read.

The assumptions for the sections to be cast are the following:

- Only one kind of section can be selected.

- The sections are squared without round corners.

- Rounded sections are other geometrical options which can be selected.

- The sections are discretized using square regular meshes. Consequently, all the elements used for discretization are identical.

The next step is to read the geometrical configuration of the CCM. Here, the radius of the curved zone $\left(r_{\mathrm{c}}\right)$, the mold length $\left(l_{\text {mold }}\right)$, the strands, and their corresponding casting speed $\left(v_{\mathrm{s}}\right)$, including their opening $\left(t_{\mathrm{o}}\right)$ and closing times $\left(t_{\mathrm{c}}\right)$, are read. The number of segments in the SCS $\left(\mathrm{ns}_{\mathrm{t}}\right)$ and the number of sprays in each segment ( $\mathrm{nsp}_{\mathrm{ns}}$ ) are also input to get the limits for the loops that will be used to read the operating conditions on every one. Finally, the length of the free zone $\left(l_{\text {free }}\right)$ is input. Logical sentences "if" are used to include warnings in order to avoid errors during reading data.

The following are the basic restrictions to read data for any CCM geometrical configuration:

- The minimum number of strands is one.

- The mold length cannot be equal or smaller than zero.

- The segments in the SCS cannot be equal or smaller than zero.

- The curved radius of the CCM cannot be equal or smaller than zero.

- A closing time cannot be shorter than an opening time.

If any of these restrictions is validated, the simulator indicates the user to make the corresponding change again. Once the geometrical configuration definition has been finished, a computational sketch of the CCM is then displayed on the screen. The mold and the segments with sprays are placed according to the information read. Then if the user is agreeing, the simulator goes to the next step; otherwise, the user can return and modify the CCM configuration.

The operating conditions must be declared also before starting the simulation. Here, the heat removal conditions are defined as a function of the geometry of the CCM. It is very 
important to know this information constitutes the boundary condition that will be applied at every moment during simulations. In the mold, the heat removal coefficients for each side of the section are read. Default values are loaded although the user can modify them, according to the heat removal rate applied. Then the operating conditions for the SCS are the next to be defined including the following:

- The diameter of the nozzle $(d)$

- The shooting angle of the nozzle $(\Omega)$

- The water flow rate $\left(V_{\mathrm{w}}\right)$

- The distance from the nozzle to the section surface $\left(d_{\text {bi-nozzle }}\right)$

All these values are read for each section side and for each segment. Thus, the subindexes, side, spray, and ns, are used to identify the side, spray, and segment, respectively. If one of these values is equal to zero, the simulator assumes that the sprays are unplugged. But if one of these values is defined with a negative value, the system will return an error on the reading data and the user is alerted to modify it accordingly.

In addition, fast definition tools also were developed to make easy to declare or modify every operating condition on every segment or every face.

\section{Discretization}

Steel billets and slabs are discretized to be analyzed dividing them into elements. Here, a steel volume is taken as a control volume and discretized as shown in Fig. 1. Each 3D element will be represented using a 2D data array, since the energy required to heat the steel until the casting temperature. $H_{\text {casting, }}$, is just a single numerical value $\left(H_{\text {casting }}=\mathrm{H}_{\mathrm{I}, \mathrm{J}}\right)$ and the subindexes I and $\mathrm{J}$ are used to indicate the nodal position. Here, Eq. (1) is solved to calculate this energy and the limits of the integrals $\left(T_{\mathrm{AR} 1}, T_{\mathrm{AR} 3}, T_{\mathrm{sol}}\right.$, and $\left.T_{\text {liq }}\right)$ are the transformation temperatures calculated as a function of the steel composition. The equations, used to obtain these temperatures, were those defined by Brimacombe et al. [1, 6].

$$
\begin{aligned}
& H_{\text {casting }}=\int_{T=T \mathrm{o}}^{T=T_{\mathrm{AR} 1}} \mathrm{Wc} \mathrm{p} \mathrm{dT}+\int_{T=T_{\mathrm{AR} 1}}^{T=T_{\mathrm{AR} 3}} \mathrm{Wc}_{\mathrm{p}} \mathrm{dT}+ \\
& \int_{T=T_{\text {sol }}}^{T=T_{\text {AR } 3}} \mathrm{Wc} \mathrm{c}_{\mathrm{P}} \mathrm{dT}+\int_{T=T_{\text {sol }}}^{T=T_{\text {liq }}} \mathrm{Wc} \mathrm{c}_{\mathrm{P}} \mathrm{dT}+\int_{T=T_{\text {liq }}}^{T} \mathrm{Wc} \mathrm{c}_{\mathrm{P}} \mathrm{dT}
\end{aligned}
$$

Here, $W$ is the element weight calculated using Eq. (2). The values for the element dimensions $\Delta x, \Delta y$, and $\Delta z$ are calculated using Eqs. (3) to (5), respectively. Here, lx and ly are the section dimensions and $\mathrm{nI}$ and $\mathrm{nJ}$ are the nodes used for discretization. The calculation of the dimension $(\Delta z)$ is obtained as a function of the casting speed on the strand ( $\left.v_{\text {strand }}\right)$
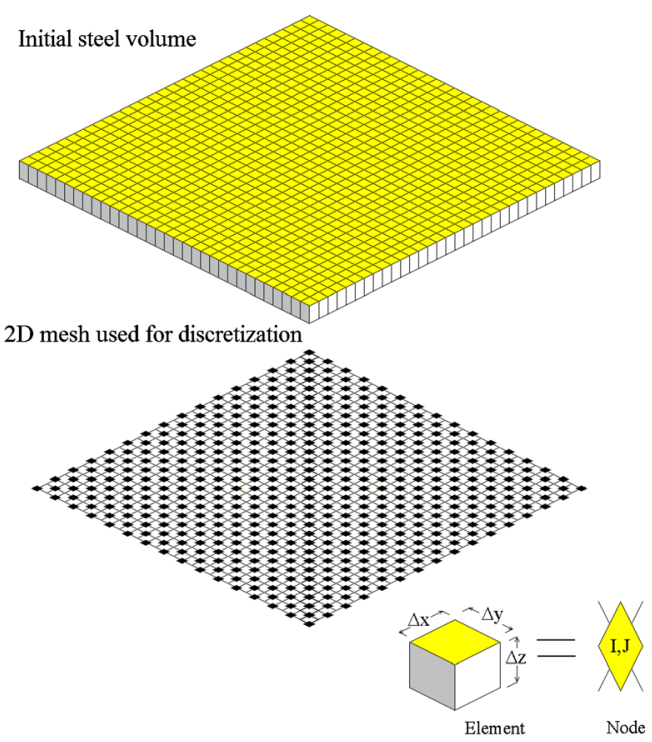

Final representation of $\left(\mathrm{T}_{1, \mathrm{~J}}\right)$ values in a format of a solidification profile.

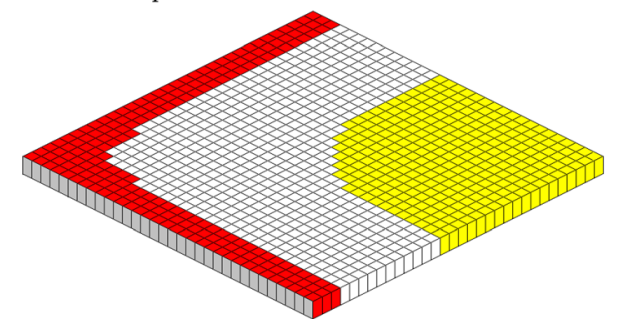

Fig. 1 Steel control volume and discretization process using a 2D array

and the calculated step time $(\Delta t)$, which is previously obtained as a function of the element size and the thermal diffusivity $(\alpha)$ solving Eqs. (6) and (7).

$w=\Delta x \Delta y \Delta z \rho_{\text {steel }}$

$\Delta x=\left(\frac{1 \mathrm{x}}{\mathrm{nI}}\right)$

$\Delta y=\left(\frac{\text { ly }}{\mathrm{nJ}}\right)$

$\Delta z=v_{\text {strand }} \Delta t$

$\alpha=\frac{k}{\rho c_{\mathrm{p}}}$

$\Delta t=\frac{\Delta x \Delta y}{4 \alpha}$

The values of the physical properties $k$ and $c_{\mathrm{p}}$ used to solve Eq. (1) correspond to the temperature range associated to each of the integrals in Eq. (1) [5, 14].

The resulted enthalpy-temperature curve obtained is shown in Fig. 2. Here, the slope changes are presented on the corresponding transformed temperatures $[15,16]$. This calculation is done one single time for one single element and assigned to 


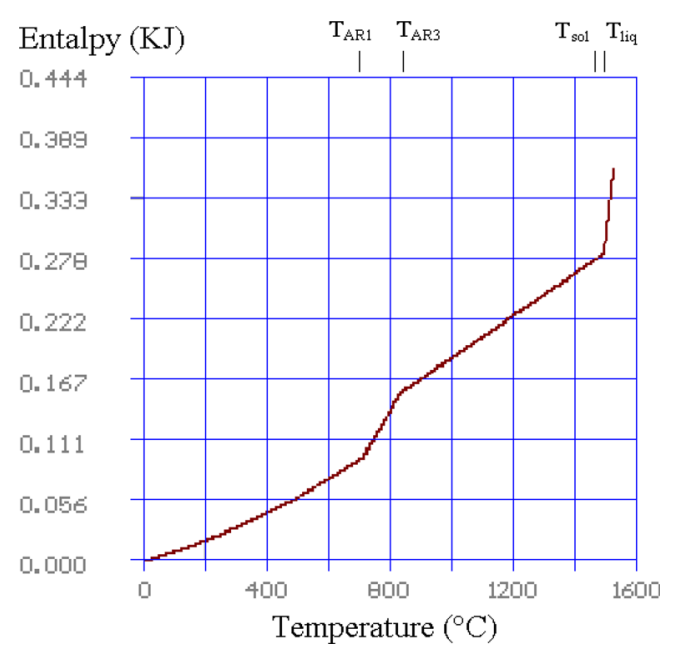

Fig. 2 Enthalpy-temperature graph obtained after solving Eq. (1) as a function of the steel composition. The changing on the curve's slope is relative with phase transformations

every element in the control volume. Then the initial assumptions for the discretization of the steel volume are the following:

- The calculated casting enthalpy is assigned to every node ( $\left.H_{\text {casting }}=H_{\mathrm{I}, \mathrm{J}}\right)$ assuming that each node is at the casting temperature $\left(T_{\text {casting }}\right)$.

- A 2D computational array and a floating point data type are used to save these values in an ordered format (rows and columns).

- Meniscus surface and control volume are flat.

The general assumptions to begin the steel thermal behavior are the following:

- Simulation begins at zero time $(t=0)$. The control volume is placed at the meniscus level.

- Casting speed remains constant during casting simulation.

- The thermal interaction on casting direction is neglected.

The following numerical code is used to recognize the section faces (lateral surfaces) where heat removal conditions will be applied considering the frontal section face as perpendicular to the casting direction:

1. For external face

2. For internal face

3. For left face

4. For right face

Then the corresponding computational loops where heat removal is applied are the following:

For the internal face $(J=\mathrm{nJ})$, the loop goes from $I=1$ to $I=\mathrm{nI}$.
For the external face $(J=1)$, the loop goes from $I=1$ to $I=\mathrm{nI}$.

For the left face $(I=1)$, the loop goes from $J=1$ to $J=\mathrm{nJ}$. For the right face $(I=\mathrm{nI})$, the loop goes from $J=1$ to $J=\mathrm{nJ}$.

The inclusion of this procedure is required because quenching conditions can be different on every face as shown in Fig. 3a, b. Different operating conditions can be defined for each face to simulate non-symmetrical heat removal. Furthermore, slabs are large sections with broad and narrow faces that require different heat removal conditions and different spray setups as can be appreciated in these figures. Nevertheless, some CCM configurations for billets casting have been modified to overcome quenching conditions. In this respect, Fig. 4a shows a segment for CCM billet casting with a symmetrical disposal. Here, 11 sprays are placed for each billet side. On the other hand, Fig. 4b shows a nonsymmetrical disposal. In this case, the internal face was considered with a critical reheating and 13 sprays were disposed. Since the algorithm employed solves a 2D array for enthalpy values $\left(H_{\mathrm{I}, \mathrm{J}}\right)$, the boundary conditions are applied using the corresponding loop for each side. The term "side" refers to a billet lateral face in the present work, and the subindex (side) is used to denote it. Then, the code number refers to the face where the heat removal conditions will be applied.

\section{Heat removal inside the mold}

The mold is the primary cooling system. A copper mold is used for steel casting, which has an efficient cooling device. The mold receives the liquid steel cast from the tundish. Here, the steel adopts an overall square shape. The solidification begins and heat removal is critical. Soon after entering into contact with the mold walls, a solid firm shell is formed as a consequence of steel cooling due to the decrement on surface temperature. This shell is a thin wall at the beginning, although its thickness must become strong enough to contain the inside mass of the liquid steel from the billet core.

The calculation of the heat removal inside the mold is a complex problem due to numerous mechanisms and materials involved. As a result, many authors [17-21] have decided to use a general equation to describe this phenomenon. Equation (8), defined by Savage and Pritchard [17], is used to provide an approximation of the heat flux removed, $q_{\text {side, from the }}$ billet surface; the values of the coefficients defined by these author are $\mathrm{Ao}=2680$ and $\mathrm{Bo}=-335$. Nevertheless, the user can modify them for each side. This computational tool was developed because the cooling system in the mold is a water recycled tubing system, placed on the mold external surfaces as shown in Fig. 5a, b. 
Fig. 3 Placing the control volume on the nodal positions. a Billet. b Slab a)

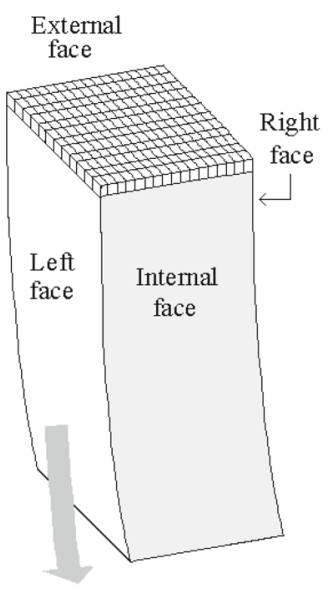

Casting direction b)

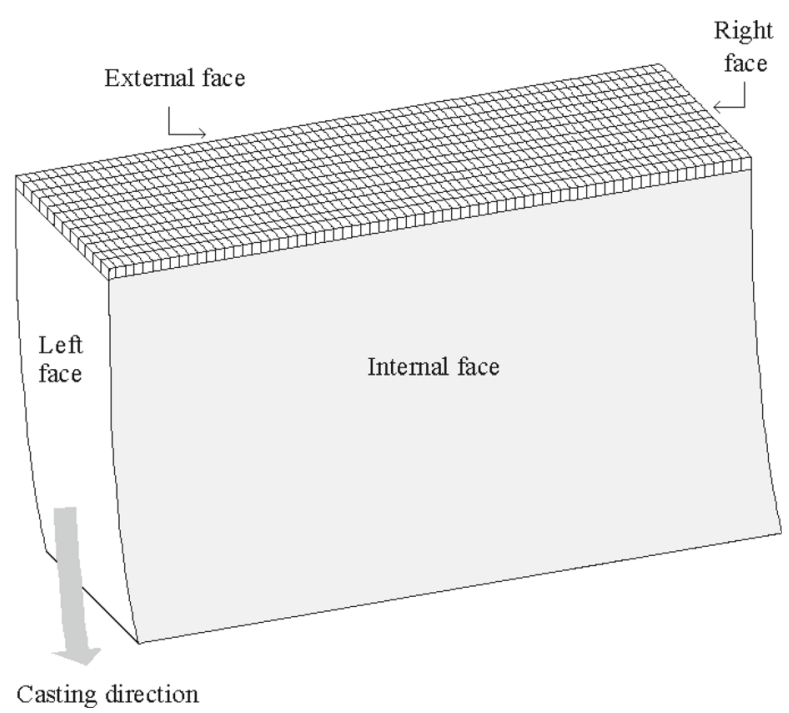

$q_{\text {side }}=\mathrm{Ao}_{\text {side }}+\mathrm{Bo}_{\text {side }} \sqrt{t_{\text {dwell }}}$

The flowchart in Fig. 6 shows the face identification procedure which is used to apply the corresponding heat removal conditions to each billet face. A subroutine for comparison, according to the lateral position, is also included for slab casting cases. A 2D array is used to store the values of heat removal and is called primary cooling system (PCS) storage data for an easy identification.

\subsection{PCS [side][data]}

The values within the first location are used to know the billet side, and data is used to store the value of the coefficients Ao and Bo and the resulting heat flux $(q)$ to be applied. This algorithm was improved from its original version developed by some of the present authors [15]. This new version includes the creation of new reading data tools and the inclusion of more complex comparisons to apply the corresponding heat removal condition to the volume of steel simulated.

\section{Heat removal in the secondary cooling system}

The SCS is formed with a group of segments where water sprays are placed along the casting direction. These sprays shoot water jets to the billet surfaces for quenching the hot section. Previous work [1-4, 6-8, 22, 23] has frequently used general equations to simulate heat removal in the sprayed areas as a function of a coefficient $(h)$, despite these equations took in account evaluations or averaged values of the surface temperatures. Consequently, these equations could not be
Fig. 4 Different spray disposal on a segment of the SCS. a Symmetrical disposal. b No symmetrical disposal

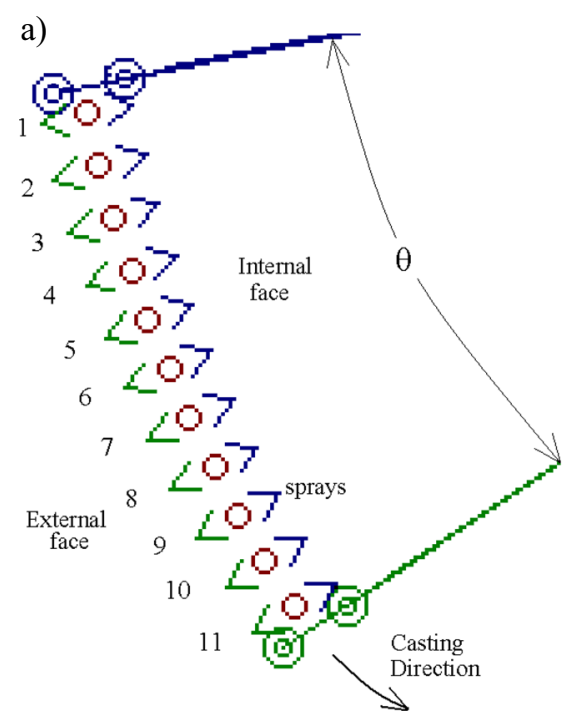

b)

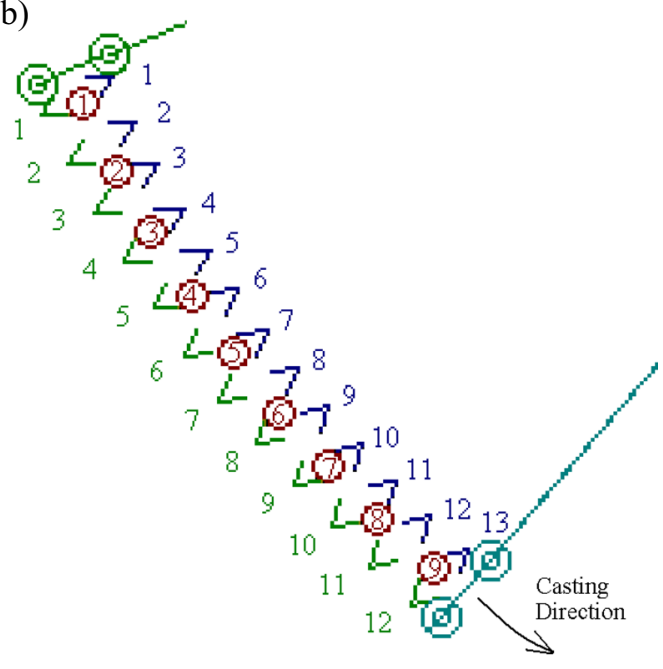


a)

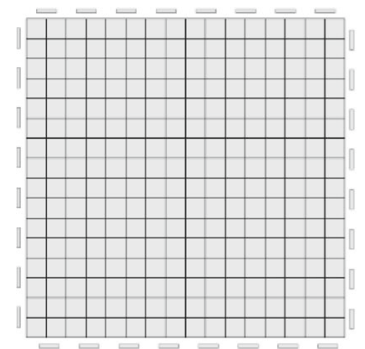

b)

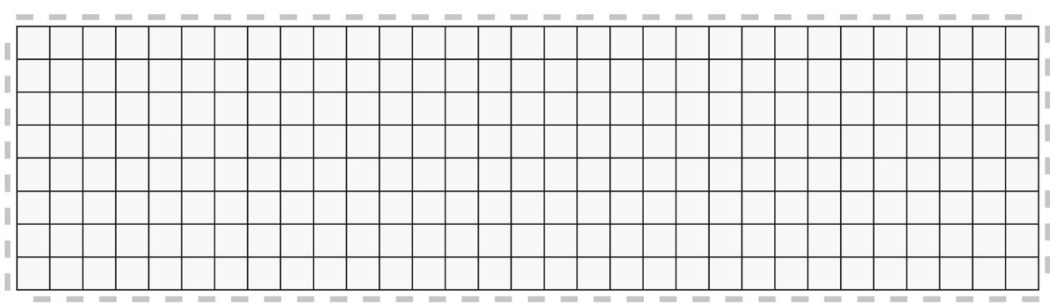

Fig. 5 Cooling system disposal for heat removal in the mold walls. a Billet. b Slab

used for a different CCM or different casting conditions. Some authors [24-27] tried to improve this initial approach defining independently different equations for each segment. Although it was hoped that they would deliver a better approach, these refinements have not provided a considerable improvement as expected. A pioneer work [28-31] was developed to evaluate heat removal in sprayed areas by interchanging physical mechanisms. Unfortunately due to limited computational capacities and undeveloped programming techniques, these models were developed slowly.

The numerical simulator developed for this work calculates every geometrical setup and displays a virtual sketch of the CCM using Eqs. (9) to (14). Then, according to the operating conditions, Eqs. (15) to (22) are used to calculate heat flux removal on the SCS and the free zone.

The calculation begins solving Eq. (9) for the length of the curved zone of the CCM $\left(l_{c}\right)$.

$l_{\mathrm{c}}=\frac{\pi r_{\mathrm{c}}}{2}$

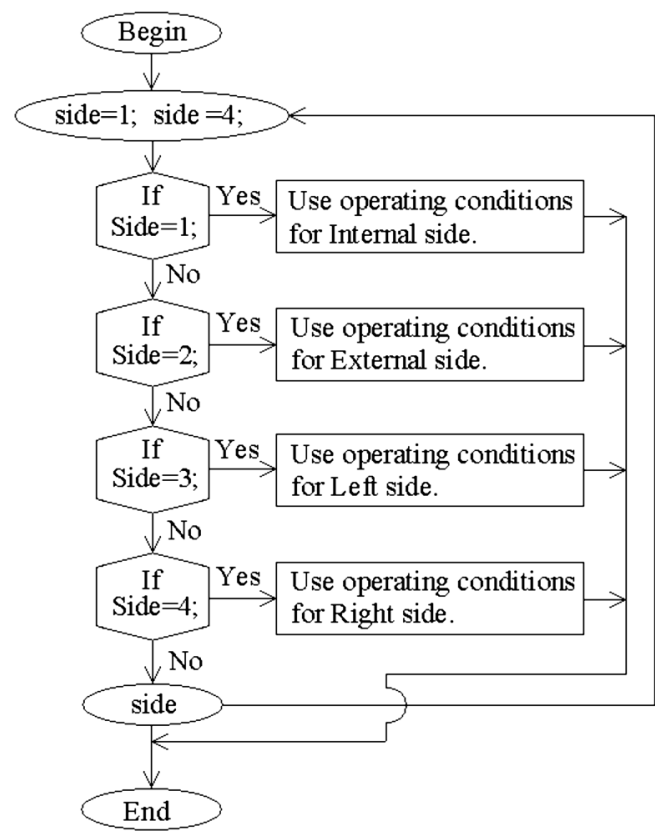

Fig. 6 Flowchart for comparison between lateral positions on the mold surfaces
Then, the total length $\left(l_{\text {tot }}\right)$ is calculated using Eq. (10); this is the total distance the steel runs along the CCM.

$l_{\text {tot }}=l_{\text {mold }}+l_{\mathrm{SCS}}+l_{\text {free-curved }}+l_{\text {free }}$

where $l_{\text {mold }}$ is the mold length, $l_{\mathrm{SCS}}$ is the SCS length, and $l_{\text {free-curved }}$ is the free zone on the curved zone. This length is calculated for the CCM designed for billet casting because the SCS is limited to the curved zone. Finally, $l_{\text {free }}$ is the length of the final straight zone where the section is driven out.

Although $l_{\text {mold }}$ is the mold length, $l_{\mathrm{m}}$ is the distance that the steel volume runs measured from the meniscus level. This value is adopted as the starting point for the beginning of the simulation. $l_{\mathrm{m}}$ is calculated using Eq. (11) and $l_{\mathrm{men}}$ is expressed in percentage.

$l_{\mathrm{m}}=l_{\text {mold }}\left(l_{\text {men }}\right)$

The length of each segment in the SCS is calculated solving Eq. (12) using nested loops.

$l_{\mathrm{ns}}=\left(\frac{\pi \theta_{\mathrm{ns}} r_{\mathrm{c}}}{180}\right)$

The length of the SCS is obtained solving Eq. (13), which represents the summation of all the partial segment lengths.

$l_{\mathrm{SCS}}=\sum_{\mathrm{ns}=1}^{\mathrm{ns}=\mathrm{ns}_{\mathrm{t}}} \frac{\pi \theta_{\mathrm{ns}} r_{\mathrm{c}}}{180}$

Once all the segment lengths have been calculated, the distance between the sprays is obtained solving Eq. (14), assuming all the sprays are uniformly disposed.

$\theta_{\text {spray }}=\left(\frac{\theta_{\mathrm{ns}}}{\mathrm{nsp}}\right)$

Then the nozzles on each segment are placed solving Eq. (15). Here, the subindexes spray- 1 and ns- 1 are used to indicate the distance between the previous spray and the previous segment, respectively. 
Fig. 7 General flowchart to know where the control volume is in order to apply the corresponding heat removal conditions
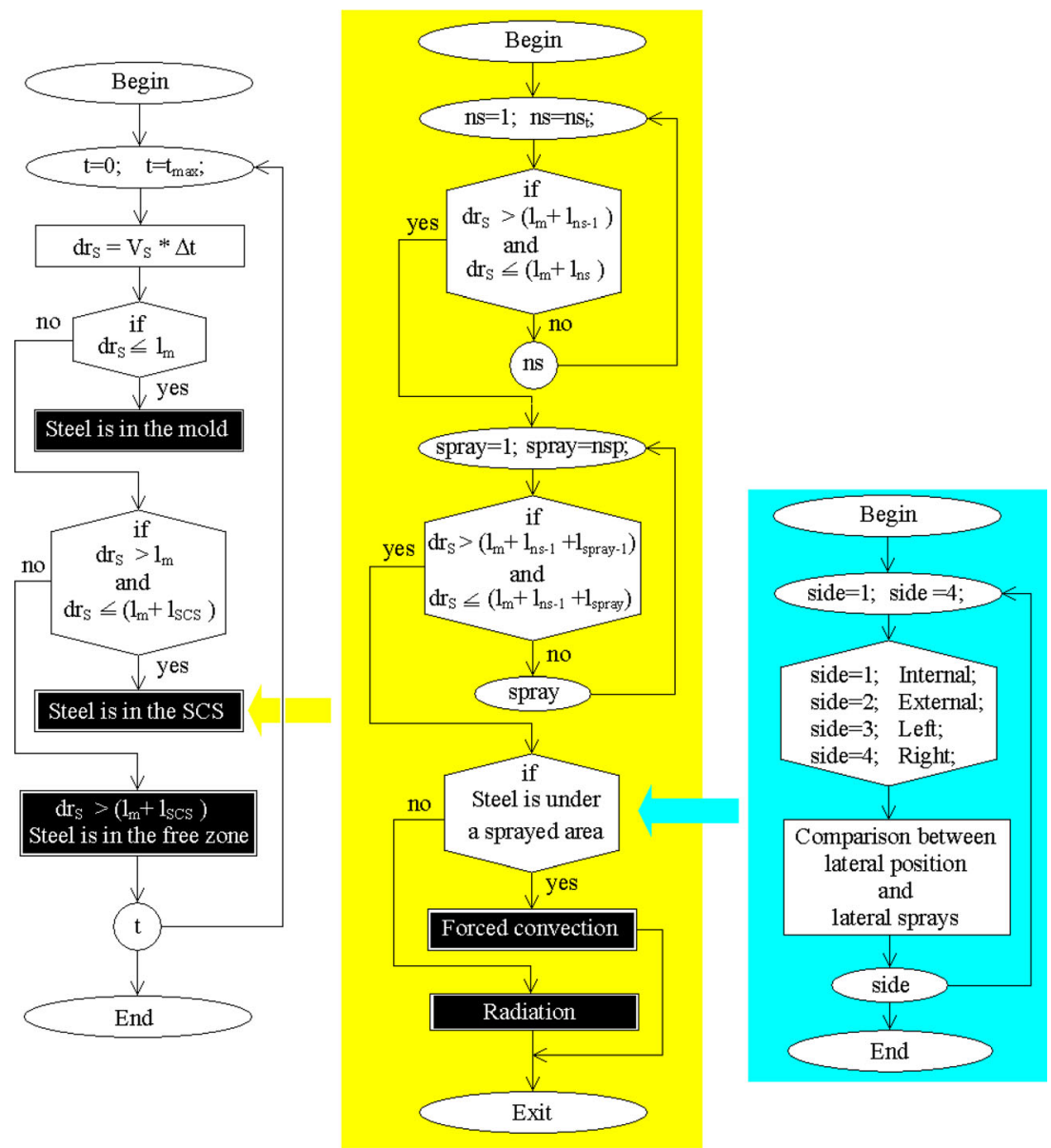

$\theta_{\text {spray }}=\theta_{\mathrm{ns}-1}+\theta_{\text {spray }-1}+\left(\frac{\theta_{\mathrm{ns}}}{\mathrm{nsp}}\right)$

The main assumptions for the geometrical configuration of the SCS are the following:

- Segments and spray are ordered.

- Sprays are placed in the middle of each segment and uniformly disposed (at the same distance one to other).

A 4D computational array is used to store all the information about the SCS as is indicated.

\subsection{SCS [segment][spray][side][data]}

Here, the first location is used to recognize the segment, which is numbered from 1 to the number of total segments $\left(\mathrm{ns}_{\mathrm{t}}\right)$. The second location is used to identify the corresponding spray. This value goes from 1 to the number of sprays in the segment $\left(n s p_{n s}\right)$. The third location is used to identify the billet side using the mentioned numerical code [15, 16, 29-31]. Symmetrical spray locations are used for casting billets whereas symmetrical water fluxes are also applied for quenching.

Nevertheless, a different configuration is used for casting slabs. Slabs are very large and require intense water flows to avoid surface reheating due to the significantly large liquid steel pool inside the core. Slabs are rectangular sections and special care should be taken to quench broad and narrow faces. Therefore, the inclusion of a matrix location for each side is a useful tool to simulate heat removal.

The fourth location in the array is used as data storage, where there are seven available places for data values of geometrical information and heat removal conditions that can be stored using a numerical code for identification, as follows:

1. Segment length $\left(l_{\mathrm{ns}}\right)$

2. Sprayed area $\left(d_{\mathrm{w} \text { ns,side }}\right)$

3. Speed of the water when it is in contact with the section surface $\left(v_{\mathrm{w} \text { ns,side }}\right)$

4. Reynolds number $\left(\operatorname{Re}_{\mathrm{ns} \text {,side }}\right)$

5. Prandtl number $\left(\operatorname{Pr}_{\mathrm{ns} \text {,side }}\right)$

6. Heat removal coefficient $\left(h_{\mathrm{ns}, \text { side }}\right)$

7. Heat removal flux $\left(q_{\text {ns,side }}\right)$ 


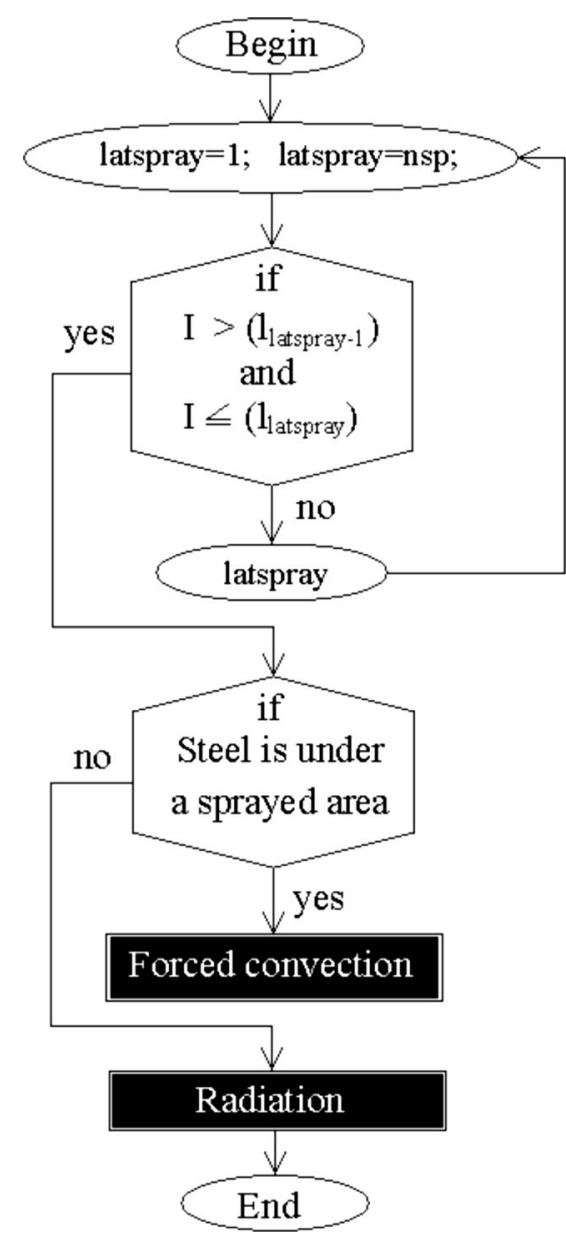

Fig. 8 Flowchart to compare lateral position for slabs broad faces

Here, the subindexes are also used as references with other variables stored in the 4D computational array. These values are calculated as follows:

The speed of water flow $\left(v_{\mathrm{w}}\right)$ is the speed of the water when takes in contact with the surface section and is obtained using Eq. (16). The length of the sprayed areas is calculated for each segment (ns) and each section face (side) solving Eq. (17) as a function of the distance from the nozzle to the billet surface $\left(d_{\text {bi-nozzle }}\right)$ and the shooting angle of the water jet $(\Omega)$.

$v_{\text {wns,side }}=\frac{v_{\text {nozzle }} A_{\text {nozzle }}}{A_{\mathrm{w}}}$
$d_{\text {wns,side }}=2 d_{\text {bi-nozzle }}\left(\tan \left(\frac{\Omega_{\text {ns,side }}}{2}\right)\right)$

Subsequently, the Reynolds (Re), Prandtl (Pr), and Nusselt $(\mathrm{Nu})$ numbers are obtained from Eqs. (17) to (19) according to the quenching conditions.

$\operatorname{Re}_{\mathrm{ns}, \text { side }}=\frac{d_{\mathrm{wns}, \text { side }} v_{\mathrm{wns}, \text { side }} \rho_{\mathrm{wns}, \text { side }}}{\mu}$
$\operatorname{Pr}_{\mathrm{ns}, \mathrm{side}}=\frac{c \mathrm{p} \mu}{k}$

$\mathrm{Nu}_{\text {ns, side }}=c \operatorname{Re}^{n} \operatorname{Pr}^{0.333}$

The values of the coefficient $(c)$ and the exponent $(n)$ are taken from reference [32], whereas the value of the coefficient $(h)$ is calculated with Eq. (21). Finally, the heat removal is obtained as a function of water temperature solving Eq. (22).

$h_{\mathrm{ns}, \text { side }}=\frac{\mathrm{Nu}_{\mathrm{ns}, \text { side }} k}{D}$

$q_{\mathrm{ns}, \text { side }}=h_{\mathrm{ns}, \text { side }}\left(T_{\mathrm{I}, \mathrm{J}}-T_{\mathrm{w}}\right)$

The comparison algorithm which allows the heat removal conditions being applied is shown in the flowchart of Fig. 7. The main routine is in the left column. This procedure is repeated for each step time as indicated in the main loop. Then the displacement of the control volume $\left(\mathrm{dr}_{\mathrm{s}}^{\mathrm{t}}\right)$ is calculated. This value is compared with the $\mathrm{CCM}$ configuration. If the first sentence is true, it means that the control volume is in the mold. Then the routine shown in Fig. 6 is applied for each side. If this sentence is false, the displacement value is compared with the SCS length. Only if the two sentences are true will means that the control volume is in the SCS. In this case, the routine in the light-shaded area in the middle column is executed. This routine is nested to determine the segment and the exact spray where the control volume is located. A pair of independent loops is run for this purpose. The first of these is used to identify the segment. This loop goes from the first segment $(n s=1)$ to the total segments $\left(n s=n_{t}\right)$ and the displacement is compared with every segment length. Then the right segment is taken only if both sentences are verified as true. After this, the second loop is run to find the spray. This loop is executed only for the taken segment and only if the two sentences check true, the right spray is taken. A final sentence is used to know if the control volume is under a sprayed area or not. This procedure is shown in the right dark-shaded column and it is nested within the previous procedure.

Figure 8 shows the flowchart of an additional routine that can be nested in the algorithm of Fig. 7. This routine is executed for slabs in order to apply the appropriate heat removal over narrow and broad faces. Here, each nodal position is compared with the lateral length of the sprayed areas (latspray). As in Fig. 7, only if both sentences are true, the forced convection algorithm is used.

The CCMs for slabs are more sophisticated than those for billets because of the greater cast steel volumes and of the 
Fig. 9 Different spray disposal for lateral faces on CCM. a For billets. b For slabs
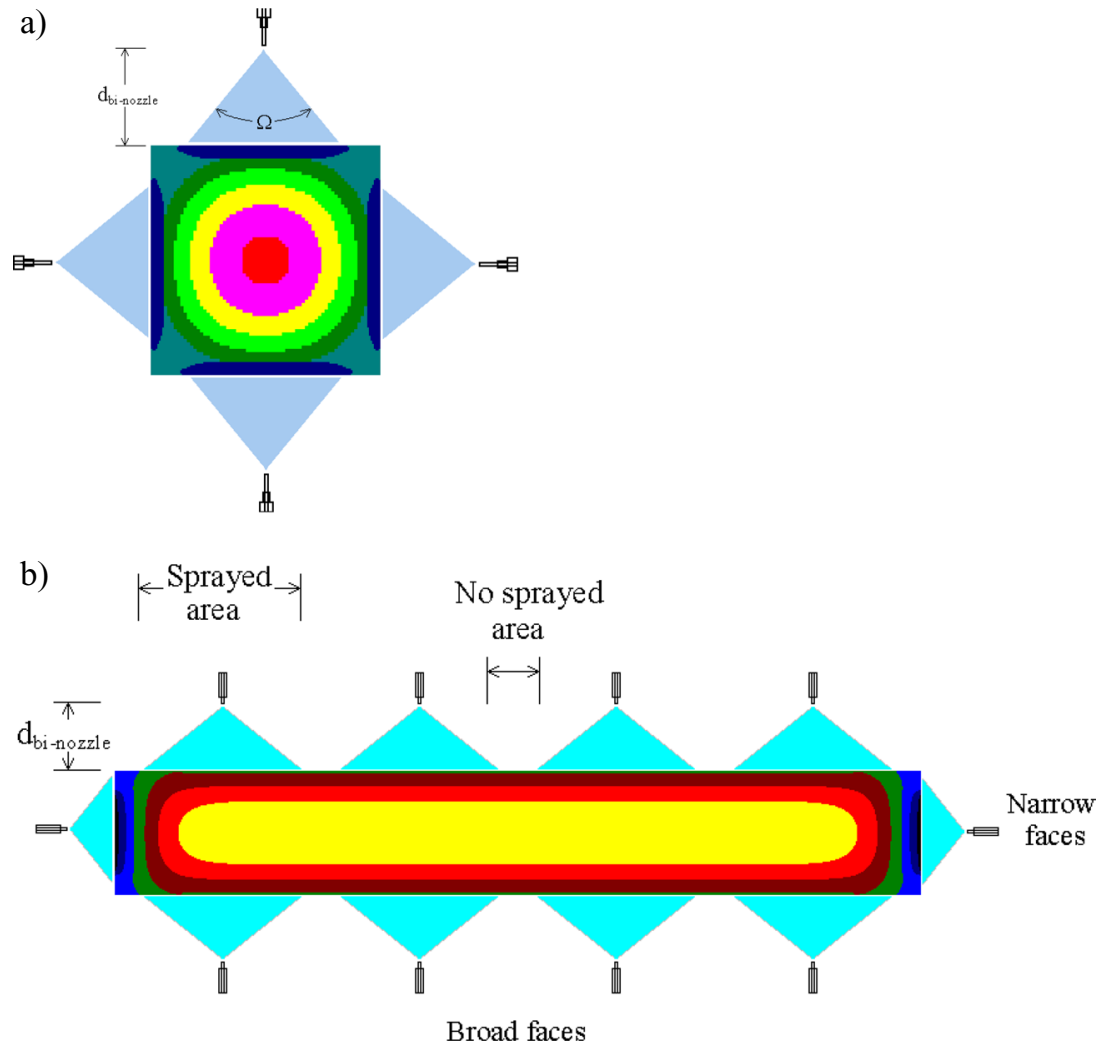

different and stronger heat removal conditions that must be applied to avoid surface reheating. Figure 9a shows a typical lateral spray arrangement for billets and Fig. 9b shows a lateral array for a slab. The comparison results in the application of different heat removal conditions. If the control volume is under a sprayed area, heat removal is strong and the surface temperature will decrease. If the control volume is under a non-sprayed area, between two spray jets, heat removal is nearly absent and the surface temperature will be increased.

The assumptions for the SCS are the following:

- Water flow rate is constant and invariable.

- Water jets are formed only with water and temperature remains always invariable during casting.

- The shooting angle $(\Omega)$ is constant; consequently, the sprayed areas are geometrically defined.

- There is no water stagnation or influence of any other heat removal mechanism.

- The angle $(\theta=0)$ is used as a reference for the CCM as shown in Fig. 10a, b. The angle $\left(\theta_{\mathrm{o}}\right)$ is the angle formed between this reference and the end of the mold. This value is assumed as the starting angle where the first segment of the SCS is placed.

According to the sketches shown in Fig. 10a, c, the CCM are very different as a function of the product to be cast billets or slabs. Figure $10 \mathrm{a}$ is with a larger curved zone and more spray segments are used because the steel volumes to be cast are majors than in the CCMs shown in Fig. 10b, c. In contrast, many spray segments and larger curved areas are needed to quench a slab as is shown in Fig. 10d.

\section{Heat removal in free zones}

In the CCM, there is a free zone at the end of the SCS where the billets and slabs are driven to be cut. Free zones can be a part of the curved zone or frequently are in the final horizontal zone of the CCM. There are no more devices to remove heat only by radiation; thus, the billet surfaces are reheated due to heat conducted from the inside core. Here, the StephanBoltzmann equation is included and solved.

$q=\varepsilon_{\text {steel }} \sigma\left(T_{\mathrm{I}, \mathrm{J}}^{4}-T_{\mathrm{amb}}^{4}\right)$

where $\varepsilon_{\text {steel }}$ is the steel emissivity and $\sigma$ is the StephanBoltzmann constant.

Moreover in the SCS, there are sprayed and non-sprayed areas; for the non-sprayed areas, the simulator also solves the Eq. (23), a reason why the temperatures on the billet surface are increased. 

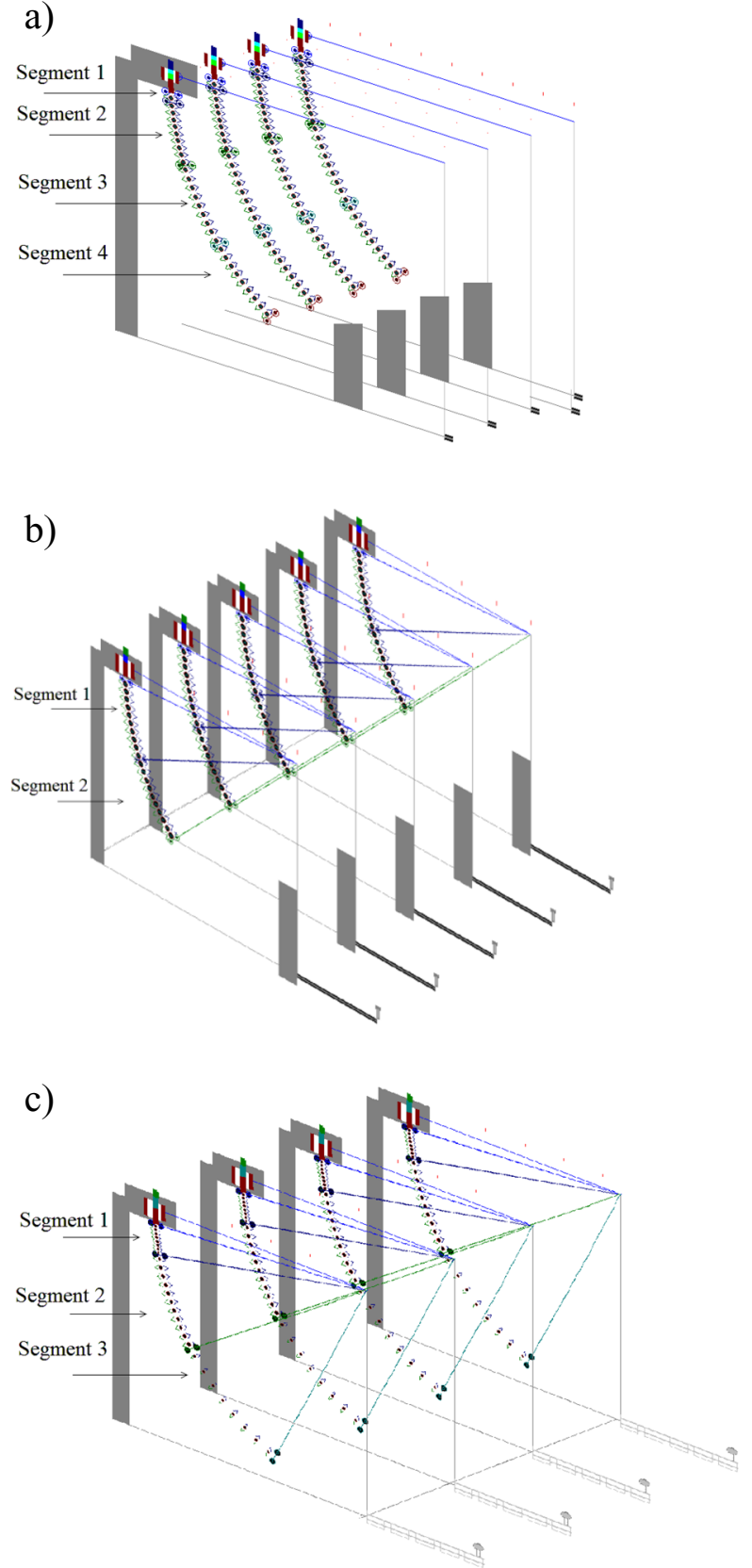

d)

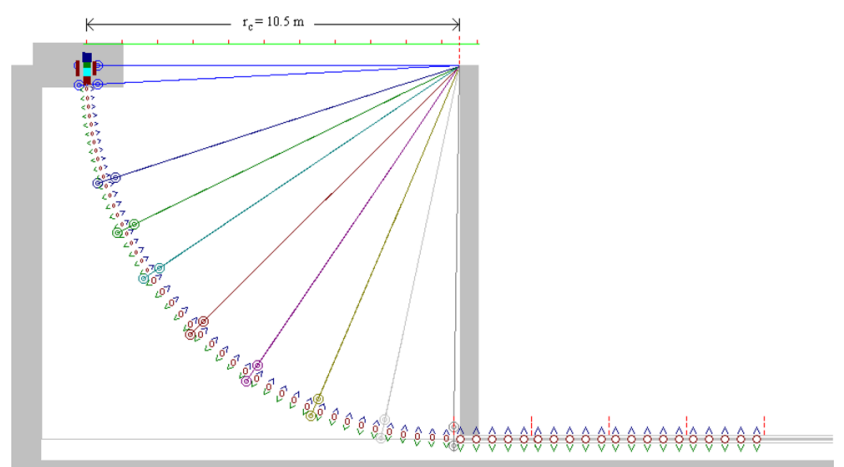

Fig. 10 Sketches of two different continuous casting machines (CCM). $\mathbf{a}-\mathbf{c}$ are $\mathrm{CCMs}$ for billet with different radius and segments corresponding to the cases 1-3 described in Tables 2, 3, and 4. d For slabs

\section{Heat flux inside the core}

Heat flux inside the cast sections is obtained solving the partial differential Eq. (24). The two terms in the left are used to indicate that there is a partial solution for the temperature on both axes $x$ and $y$ for the 2D steel volume. The contribution of the third term is zero because heat transfer on the casting direction has been neglected. The solution is also a function of the physical properties and the simulation time, as indicated by the right-hand term. A finite difference method known as the Cranck-Nicholson rule [33, 34] was employed to solve this equation system.

$\frac{\partial}{\partial x}\left(k \frac{\partial T}{\partial x}\right)+\frac{\partial}{\partial y}\left(k \frac{\partial T}{\partial y}\right)+\frac{\partial}{\partial z}\left(k \frac{\partial T}{\partial z}\right)+q=\rho c_{p} \frac{\partial T}{\partial t}(24)$

Equation (24) can also be written as Eq. (25) [35, 36]; the terms in this partial equation can be replaced by those in Eq. (26) where the temperature with subindexes I and J are used to represent the nodal positions of each

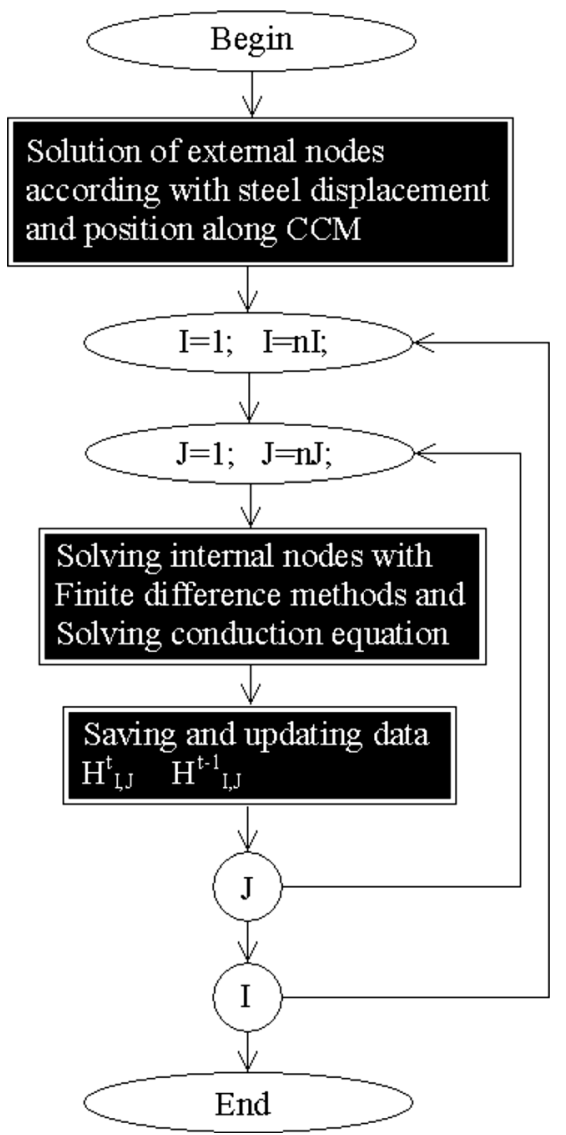

Fig. 11 General flowchart for calculating heat transfer at each step time 


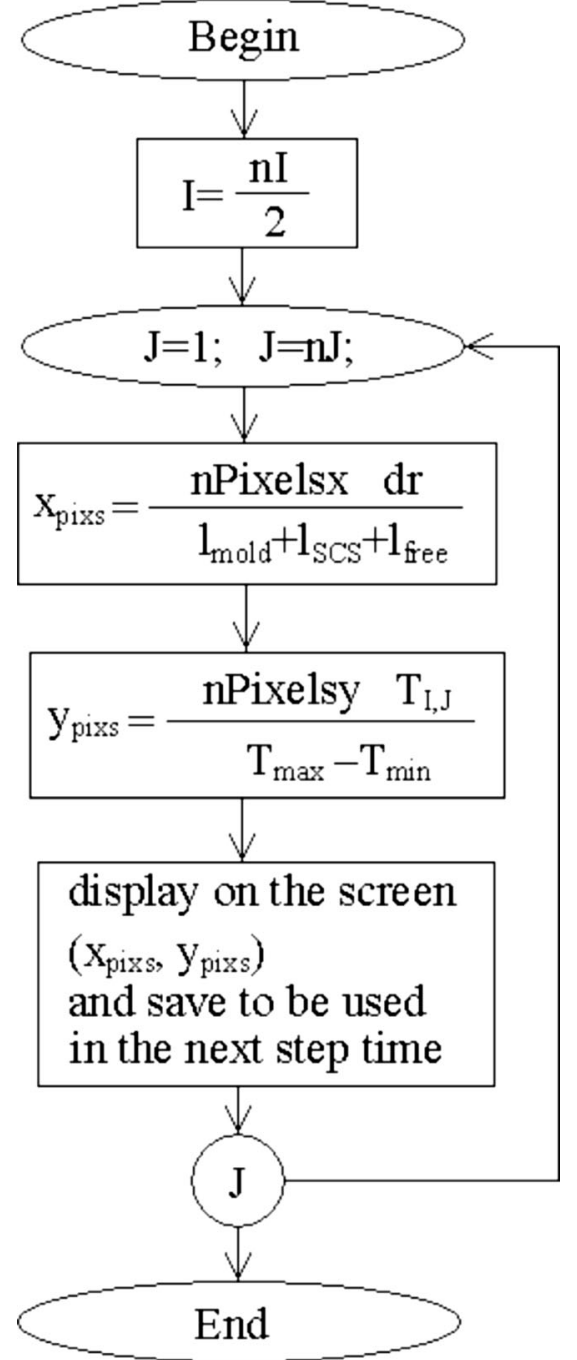

Fig. 12 Flowchart of the algorithm to display line graphs for temperature on the computer screen

discretized element (the pivoting nodes and nearest neighbors). These values can also be replaced by enthalpies to make the same assessment. The interchange is assumed as valid because every temperature value is directly related to the corresponding enthalpy value.

$\frac{\partial^{2} T}{\partial x^{2}}+\frac{\partial^{2} T}{\partial y^{2}}=\frac{1}{\alpha} \frac{\partial T}{\partial t}$

Table 1 Sentences for comparison to get the corresponding color for the nodes according to its temperature

\begin{tabular}{ll} 
1. $T_{\mathrm{I}, \mathrm{J}}<T_{\mathrm{AR} 1}$ & Steel is solid \\
2. $T_{\mathrm{AR} 1}<T_{\mathrm{I}, \mathrm{J}}<T_{\mathrm{AR} 3}$ & \\
3. $T_{\mathrm{AR} 3}<T_{\mathrm{I}, \mathrm{J}}<T_{\mathrm{sol}}$ & \\
4. $T_{\mathrm{sol}}<T_{\mathrm{I}, \mathrm{J}}<T_{\text {liq }}$ & Steel is in mushy \\
5. $T_{\mathrm{I}, \mathrm{J}}>T_{\mathrm{liq}}$ & Steel is liquid \\
\hline
\end{tabular}

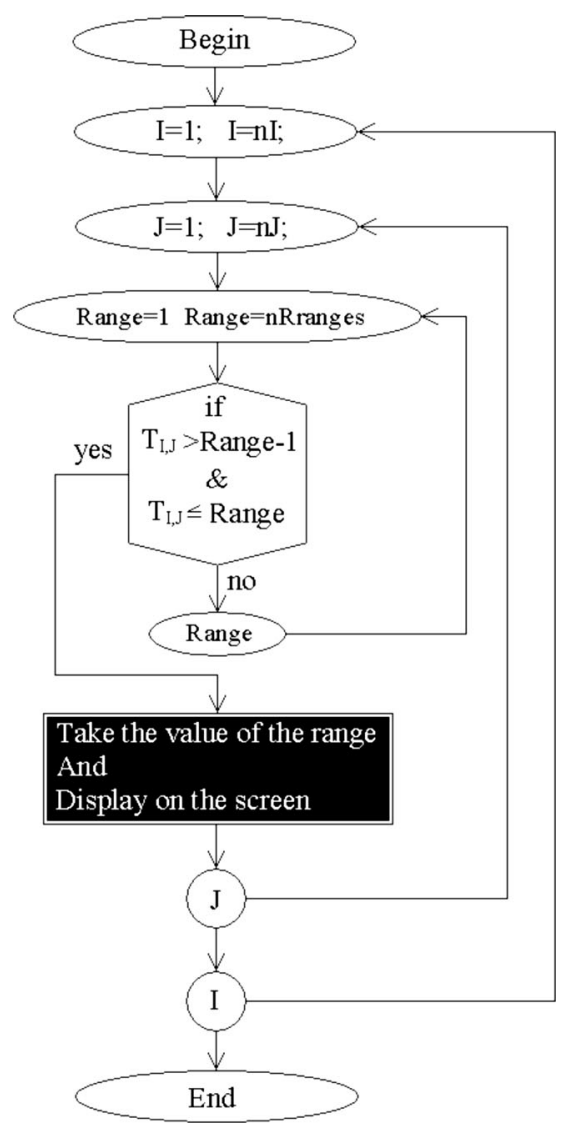

Fig. 13 Flowchart for creating a temperature profile with established ranges on the computer screen

$$
\begin{aligned}
& \frac{1}{(\Delta x)^{2}}\left(T_{\mathrm{I}-1, \mathrm{~J}}+T_{\mathrm{I}+1, \mathrm{~J}}-2 T_{\mathrm{I}, \mathrm{J}}\right) \\
& +\frac{1}{(\Delta y)^{2}}\left(T_{\mathrm{I}, \mathrm{J}-1}+T_{\mathrm{I}, \mathrm{J}+1}-2 T_{\mathrm{I}, \mathrm{J}}\right) \\
& =\frac{1}{\alpha_{\mathrm{I}, \mathrm{J}}} \frac{T_{\mathrm{I}, \mathrm{J}}^{\mathrm{t}+1}-T_{\mathrm{I}, \mathrm{J}}^{\mathrm{t}}}{\Delta t}
\end{aligned}
$$

Equation (26) can be easily programmed and solved using a pair of nested loops for every nodal position. The finite difference method is useful due its simplicity and also because

Table 2 General configuration of the CCM for casting billets

\begin{tabular}{lccc}
\hline CCM (case) & 1 & 2 & 3 \\
\hline Casting speed (m/min) & 2.35 & 2.20 & 2.20 \\
Casting temperature (C) & 1527 & 1540 & 1531 \\
$r_{\mathrm{c}}(\mathrm{m})$ & 9.5 & 5.0 & 5.6 \\
$\theta_{0}$ & 6 & 5 & 5.5 \\
Dx $(\mathrm{mm})$ & 160 & 130 & 127 \\
Dy $(\mathrm{mm})$ & 160 & 130 & 127 \\
Mold $(\mathrm{m})$ & 0.90 & 0.95 & 0.90 \\
Meniscus $(\%)$ & 80 & 80 & 80 \\
\hline
\end{tabular}


Table 3 Operating conditions of the SCS for different CCM configurations (for billets)

\begin{tabular}{|c|c|c|c|c|c|c|c|c|c|}
\hline \multirow{2}{*}{$\begin{array}{l}\text { CCM config. (case) } \\
\text { Segment }\end{array}$} & \multicolumn{4}{|l|}{1} & \multicolumn{2}{|l|}{2} & \multicolumn{3}{|l|}{3} \\
\hline & 1 & 2 & 3 & 4 & 1 & 2 & 1 & 2 & 3 \\
\hline Water flow rate $(1 / \mathrm{min})$ & 192 & 250 & 210 & 210 & 175 & 148 & 107 & 220 & 147 \\
\hline Sprays & 1 & 9 & 9 & 9 & 10 & 10 & 8 & 11 & 8 \\
\hline$\theta$ & 2 & 12.6 & 16 & 16 & 20 & 20 & 7.5 & 22.5 & 30 \\
\hline$\Omega$ & 60 & 60 & 60 & 60 & 55 & 55 & 80 & 60 & 60 \\
\hline$D_{\mathrm{bs}}(\mathrm{mm})$ & 160 & 160 & 160 & 160 & 150 & 150 & 60 & 110 & 75 \\
\hline
\end{tabular}

data management is not complicated, and the responses can be obtained quickly. A pair of nested loops for the I and J nodal positions was programmed using $\mathrm{C}++$ to solve every new temperature value $\left(T_{\mathrm{I}, \mathrm{J}}^{\mathrm{t}}\right)$ and the procedure is repeated at every step time during simulation $(t+\Delta t)$.

\section{Numerical solution}

Figure 11 shows the general flowchart that computes the steel thermal behavior. This algorithm is executed at each step time $(t+\Delta t)$. The external nodes are solved using the corresponding heat removal conditions for each side. Only external nodes are exposed to heat removal. Then the conduction equation is solved for all nodes to calculate the distribution of the internal latent heat. Figure 11 shows the corresponding pair of nested loops used to solve Eq. (26) for every node of the steel volume and how the process is repeated at every moment during the simulation. Two computational arrays are used to store the enthalpy values in an ordered format. One of them is initialized with the original conditions $\left(H_{\mathrm{I}, \mathrm{J}}=H_{\text {casting }}\right)$. After the execution of the solving routine, the new array is used to store the results of the final calculation $\left(H_{\mathrm{I}, \mathrm{J}}^{\mathrm{t}}\right)$. These values are updated in the second step time and the remaining process is repeated saving the latest values $\left(H_{\mathrm{I}, \mathrm{J}}^{\mathrm{t}}\right)$ and the previous $\left(H^{\mathrm{t}}\right.$ $\left.{ }_{\mathrm{I}, \mathrm{J}}\right)$. The same loops in Fig. 11 are used to avoid unnecessary computer code and work.

The general flowchart shown in Fig. 7 is nested in the subroutine in Fig. 11 at the beginning of the process to calculate the external and the internal nodes, respectively.
In order to make a brief overview of the process, the use of every equation is described next:

Equations (1) to (5) are used to explain how the total heat needed to foundry the steel volume was calculated; then the resulted value an enthalpy $(H)$ was assigned to every node; every node will represent an element of the discretized steel.

Equations (6) and (7) are used to explain the calculation of an appropriated step time $(\Delta t)$ for the simulation.

Equations (8) to (23) are employed to calculate the geometrical configuration of the continuous casting machine and how the boundary conditions for the heat removal are assigned; many of these calculations require of some additional calculation as is described (for example forced convection parameters involved). These equations are solved immediately, the establishment of the boundary conditions has been finished and are calculated only one single time, and the values for the heat removal $(q)$ are stored in a computational array to be applied as a function of the volume of steel position along the $\mathrm{CCM}$ at every moment.

Equations (24) and (26) are partial differential equations which show the partial solution of the heat transfer phenomenon analyzed at every step time for every nodal position. In this way, Eq. (26) is an algebraic form of the Eq. 25. Here, the temperatures on every node and the surrounding neighbors are represented; this equation can be programmed to be solved computationally in an algorithm. The influence of the heat removal $(q)$ is assumed as negative due to the heat that is being taken out of the steel on the lateral surfaces; $(q)$ is a function of the CCM configuration and the casting conditions, and thus, Eqs. (8), (22) and (23) are used to establish it and the complete algorithm is described in Figs. 6, 7, and 8.

Table 4 Composition of cast steel (\%)

\begin{tabular}{|c|c|c|c|c|c|c|c|c|c|c|c|c|c|c|}
\hline \multirow[t]{2}{*}{ Case } & \multicolumn{14}{|c|}{ Element } \\
\hline & $\mathrm{C}$ & $\mathrm{Al}$ & $\mathrm{Cr}$ & $\mathrm{Cu}$ & $\mathrm{Mn}$ & $\mathrm{Nb}$ & Mo & $\mathrm{Ni}$ & $\mathrm{P}$ & $\mathrm{Ti}$ & $\mathrm{S}$ & $\mathrm{Si}$ & $\mathrm{Sn}$ & V \\
\hline 1 & 0.380 & 0.003 & 0.005 & 0.040 & 1.050 & 0.002 & 0.002 & 0.006 & 0.014 & 0.002 & 0.018 & 0.200 & 0.001 & 0.002 \\
\hline 2 & 0.355 & 0.005 & 0.003 & 0.025 & 0.500 & 0.005 & 0.004 & 0.010 & 0.010 & 0.003 & 0.015 & 0.350 & 0.004 & 0.005 \\
\hline 3 & 0.400 & 0.006 & 0.004 & 0.032 & 0.450 & 0.005 & 0.003 & 0.005 & 0.025 & 0.009 & 0.015 & 0.125 & 0.002 & 0.007 \\
\hline Slab & 0.085 & 0.005 & 0.009 & 0.025 & 0.420 & 0.001 & 0.001 & 0.002 & 0.016 & 0.009 & 0.007 & 0.130 & 0.001 & 0.000 \\
\hline
\end{tabular}




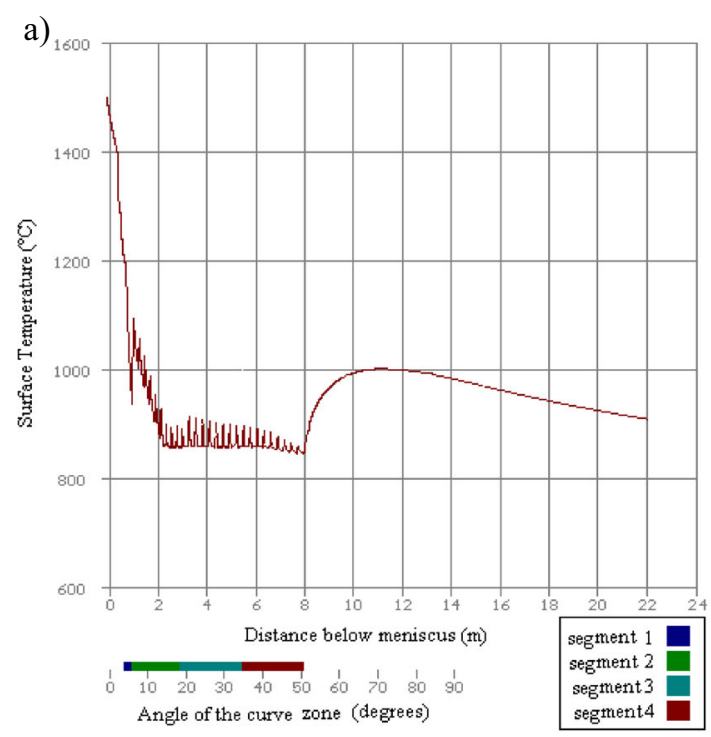

c)

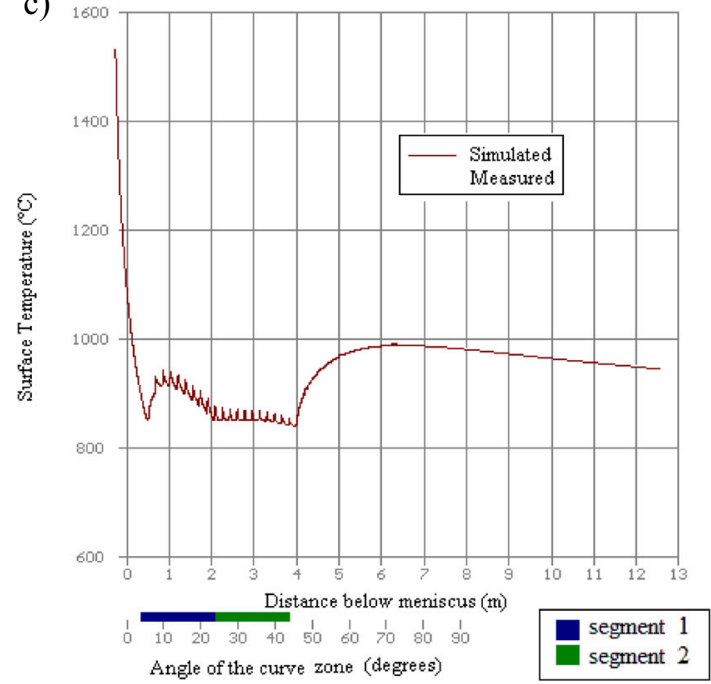

b)

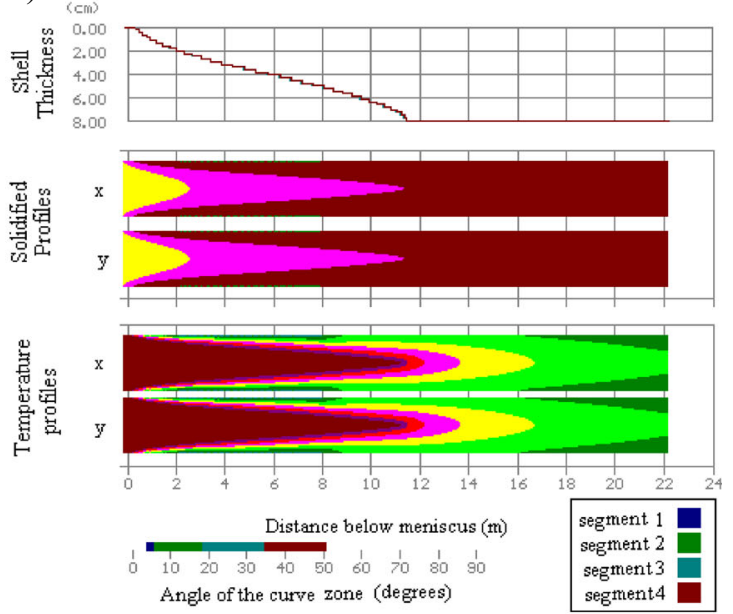

d) $\quad$ (cmil
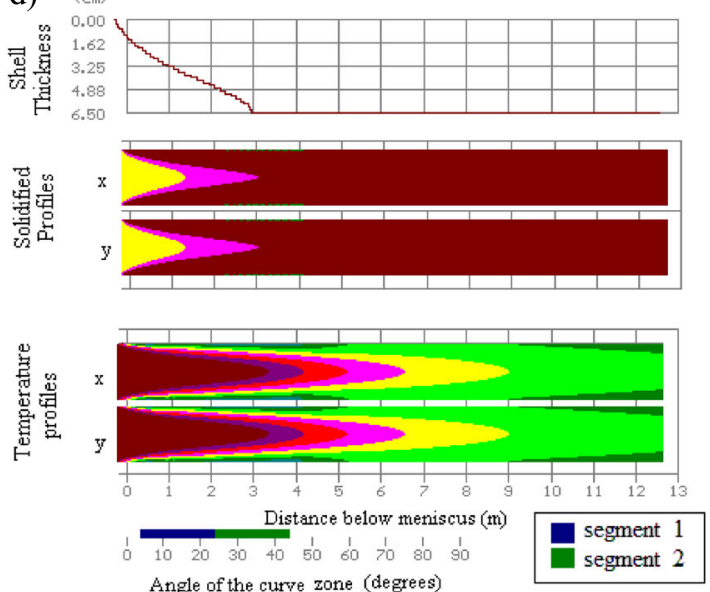

Fig. 14 Simulations on different CCMs for validations. a, b For case 1. c, d For case 2

\section{Graphical tools and algorithms}

Computational algorithms were developed in the present work for displaying the obtained results. A graphical user interface (GUI) is executed with the appropriate and logical procedures to display on screen different kinds of graphical information for the steel thermal behavior. These routines were compiled using independent files and algorithms in order to avoid repeating unnecessary code.

Line graphs are used to display temperature values for a nodal position. These graphs are displayed using the algorithm of Fig. 12. Here, the nodal position for the $(I)$ elements is fixed in the middle position of the cast section $(I=\mathrm{nI} / 2)$ but the nodal positions for the perpendicular axis are a function of the loop for $J$. The equations shown in the process are solved and the obtained position is graphed on the computer screen. The variables nPixelsx and nPixelsy are established as scales to fit within the computer display. The values of the temperatures $T_{\max }$ and $T_{\min }$ are assumed as $T_{\max }=1600{ }^{\circ} \mathrm{C}$ and $T_{\min }=600{ }^{\circ} \mathrm{C}$. These temperatures are considered as the most appropriate upper and lower limits.

Temperature and solidification profiles are displayed in two formats, namely, 2D and 3D. The profiles in the 2D format can be displayed for a longitudinal cut along the casting direction in order to observe the steel thermal behavior and the solidification profiles during simulation.

The algorithm developed for displaying temperature profiles is shown in Fig. 13. Here, every nodal value is analyzed using the internal loop. nRanges is an integer data type which represents the number of ranges to be used for classifying. The value of each range is previously calculated using Eq. (27). Then a numerical code is assigned to each range to identify and display the corresponding color on the screen. The internal loops compare 
Fig. 15 a Temperatures at different nodal positions from the billet surface towards the core. $\mathbf{b}$ Close-up of the temperature over the billet surface (to evidence quenching on the billet surface under the sprayed areas and reheating on the non-sprayed) a)

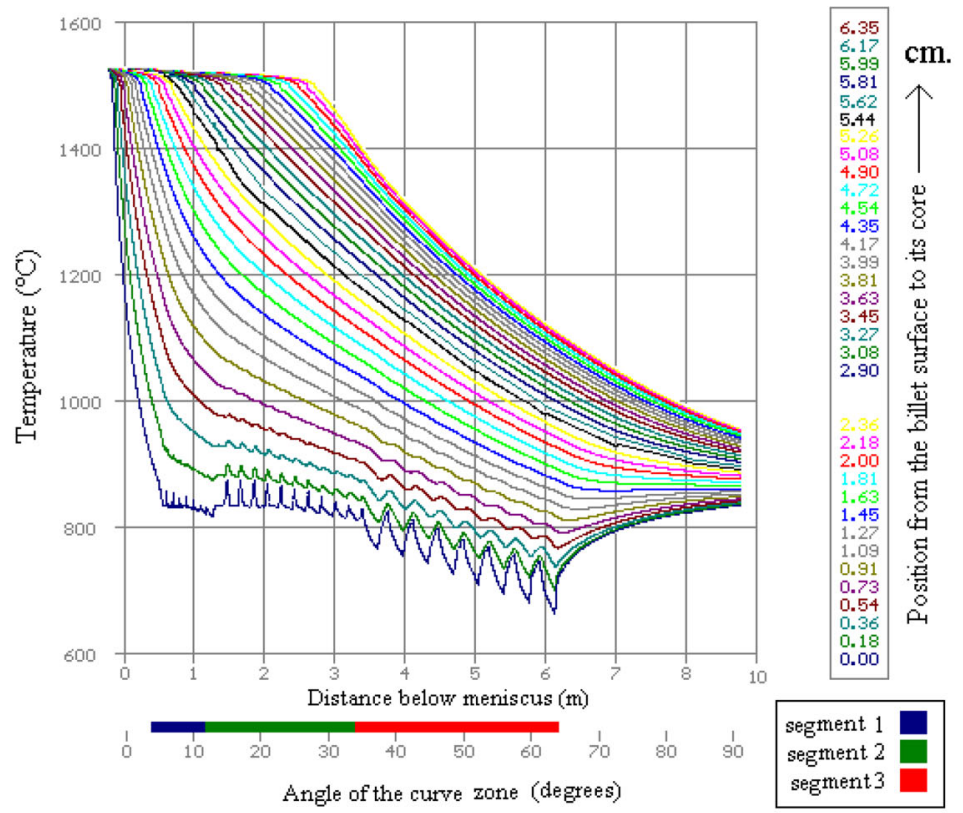

b)

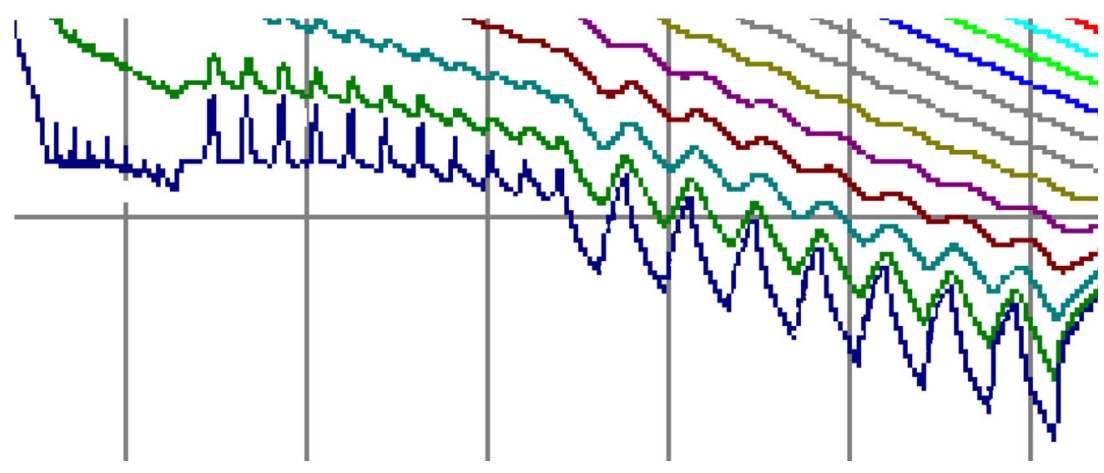

each nodal temperature $\left(T_{\mathrm{I}, \mathrm{J}}\right)$, and only if the two sentences inside are true, the value of the range is taken and displayed on the screen.

$T_{\text {range }}=\frac{T_{\max }-T_{\min }}{\text { nRanges }}$

In other words, every nodal temperature $\left(T_{\mathrm{I}, \mathrm{J}}\right)$ is treated as in a searching process for finding the correct color to display the image.

A very similar procedure is used to create the solidification profiles. But five ranges must be defined according to the temperatures $\left(T_{\mathrm{AR} 1}, T_{\mathrm{AR} 3}, T_{\mathrm{sol}}\right.$, and $\left.T_{\text {liq }}\right)$. Then the comparison on the Table 1 must be verified to illustrate the nodal state with a numerical code.

The same nested loops shown in Fig. 13 are used to make the comparison for all the temperature values $\left(T_{\mathrm{I}, \mathrm{J}}\right)$ with the restrictions indicated using sentences "if," and then the solidification profile is displayed on the screen.

\section{Simulations and analysis}

The computational language used to develop the simulator was $\mathrm{C}++$. Nevertheless, the algorithms shown are the logical procedures created and these can be programmed using any other programming language. A GUI was developed to display on the screen different options for the results such as line and pixel graphics.

In order to validate the results obtained with the algorithm developed, a comparison with real temperature values was done. Tables 8, 9, and 10 show the comparison with the 3 cases described in Tables 2, 3, and 4. Real temperature values were taken directly in the SCS using a digital pyrometer where available; casting is a dangerous and delicate process reason why only a few zones are accessible during the casting operation. In these tables, the every value measured was averaged from a set of 12 lectures during casting. And the simulated temperatures were saved from the computer simulation. The simulations for cases 1 and 2 can be appreciated on Fig. 14ad. A good approach to predict the steel thermal behavior was 
Temperature $\left({ }^{\circ} \mathrm{C}\right)$

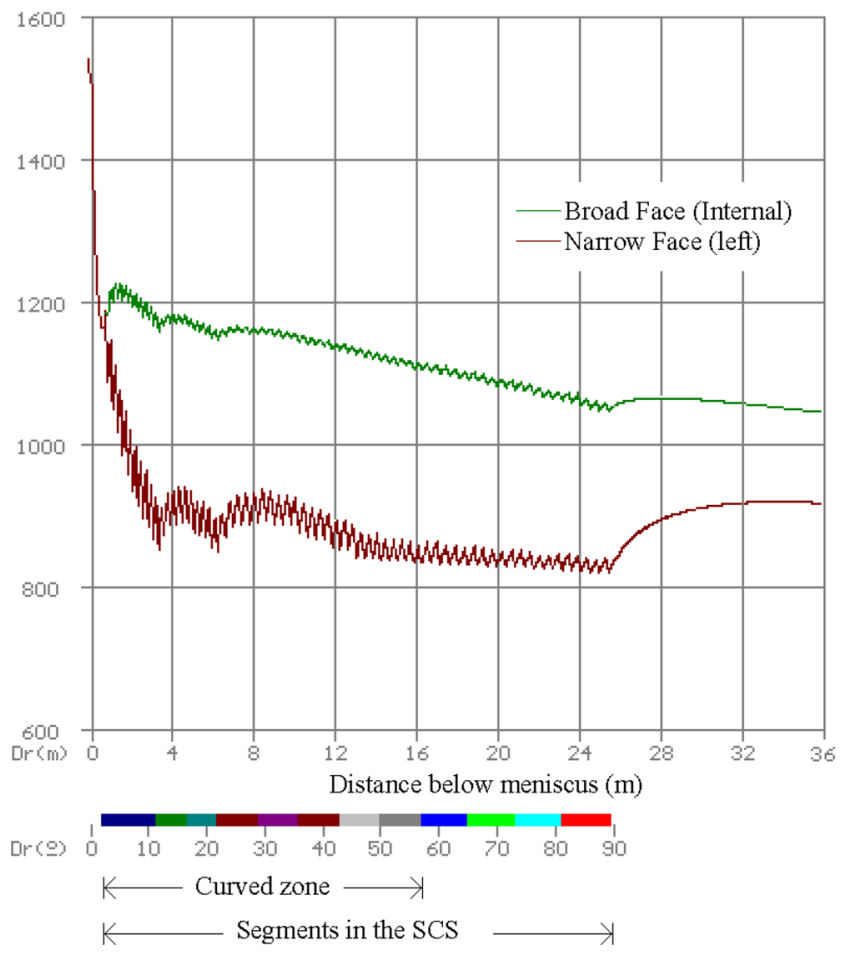

Fig. 16 Comparison between surface temperature on the broad and narrow faces of a slab

obtained with the algorithm developed as is proven in Tables 8, 9, and 10. Here, the major differences were in the SCS and in the free zone, all the temperatures in the billet tend to adopt a homogeneous temperature; thus, the variation is minimum. Here, the difference between the simulated and real temperatures $\left(T_{\text {sim }}\right.$ and $\left.T_{\text {real }}\right)$ was also minimum.

Figure 15 shows a lineal graph for a billet cast using a CCM with the configurations described in Table 2 and the operating conditions employed are shown in Table 3; steel composition is described in Table 4 and the CCM configuration was previously shown in Fig. 10c, all these correspond for case (3). The scales in the horizontal axis of Fig. 15 refer to the steel control volume advance and its position along the curved zone. The meniscus level for the billet cast is slightly above the reference line of the CCM for the angle $(\theta=0)$, that is why this graph starts before the horizontal position of the CCM. Here, a continuous decrement on surface temperature can be

Table 5 General configuration of the CCM for casting slabs

\begin{tabular}{ll}
\hline Casting speed $(\mathrm{m} / \mathrm{min})$ & 1.25 \\
Casting temperature $(\mathrm{C})$ & 1545 \\
$r_{\mathrm{c}}(\mathrm{m})$ & 10.5 \\
$\theta_{0}$ & 23.5 \\
Dx $(\mathrm{mm})$ & 200 \\
Dy $(\mathrm{mm})$ & 1500 \\
Mold $(\mathrm{m})$ & 1.00 \\
Meniscus $(\%)$ & 82 \\
\hline
\end{tabular}

Table 6 Dimensions and operating conditions of the SCS in the curve zone (for slabs)

\begin{tabular}{lrlllllll}
\hline Zone & $\theta$ & $\Sigma \theta$ & $\begin{array}{l}\mathrm{Rd} \\
(\mathrm{m})\end{array}$ & $\Omega$ & Sprays & $\begin{array}{l}\mathrm{ds}{ }_{\mathrm{ZN}} \\
(\mathrm{mm})\end{array}$ & $\begin{array}{l}\mathrm{dw}{ }_{\mathrm{ZN}}^{\prime} \\
(\mathrm{mm})\end{array}$ & $\begin{array}{l}\mathrm{dnw}_{\mathrm{ZN}}^{\prime} \\
(\mathrm{mm})\end{array}$ \\
\hline 1 & 12 & 18 & 3.29 & 60 & 11 & 500 & 329 & 171 \\
2 & 8 & 26 & 4.76 & 55 & 5 & 500 & 467 & 33 \\
3 & 8 & 34 & 6.23 & 50 & 5 & 500 & 467 & 33 \\
4 & 11 & 45 & 8.24 & 50 & 5 & 750 & 660.5 & 89.5 \\
5 & 11 & 56 & 10.26 & 50 & 5 & 750 & 660.5 & 89.5 \\
6 & 11 & 67 & 12.28 & 50 & 5 & 750 & 660.5 & 89.5 \\
7 & 11 & 78 & 14.29 & 50 & 5 & 750 & 660.5 & 89.5 \\
8 & 10 & 88 & 16.3 & 50 & 5 & 750 & 660.5 & 89.5 \\
\hline
\end{tabular}

observed on the mold because the heat is removed along the mold walls. Different heat removal conditions can be appreciated on the SCS. The influence of the water spray jets distribution is noted here; in the first segment, the jets are very close and non-sprayed areas are nearly absent. In segments 2 and 3, there are long non-sprayed areas and surface reheating can be appreciated. A final surface reheating at the end of the SCS is due to latent heat flowing out inside the core. Reheating continues until a maximum temperature is reached and then it decreases slowly. In Fig. 15, the surface temperature variation is large due to the intense heat removal and long non-sprayed areas. Nevertheless, the variation is small inside the billet core and the temperature curves are closed and continuous due to the conduction of heat inside the billet. The change on the graph slopes inside the core is due to temperature transformations from liquid to mushy and from mushy to solid. Finally, all temperatures tend to a unique value at the end due to latent heat distribution coming from inside the core. It is important to mention that the theoretical description for the billet surface temperatures (dark blue line $(0 \mathrm{~cm})$ ) agrees well with the experimental temperature recorded on real billets, measured with the aid of a pyrometer.

Figure 16 shows the graph for a slab cast with the graphical configuration described in Table 5. The CCM was previously shown in Fig. 10d; for slabs, due to the CCM complexity, Tables 6 and 7 are used to describe the SCS configuration and the heat removal conditions for the sprayed segments on the curved and straight zones, respectively. The values of the

Table 7 Dimensions and operating conditions of the SCS out the straight zone

\begin{tabular}{ccccccc} 
Zone & $\mathrm{Rd}(\mathrm{m})$ & $\Omega$ & Sprays & $\mathrm{ds}_{\mathrm{ZN}}^{\prime}(\mathrm{mm})$ & $\mathrm{dw}_{\mathrm{ZN}}^{\prime}(\mathrm{mm})$ & $\mathrm{dnw}_{\mathrm{ZN}}^{\prime}(\mathrm{mm})$ \\
\hline 9 & 18.61 & 55 & 5 & 750 & 630.4 & 119.6 \\
10 & 20.92 & 55 & 5 & 750 & 630.4 & 119.6 \\
11 & 23.22 & 55 & 5 & 750 & 630.4 & 119.6 \\
12 & 25.52 & 55 & 5 & 750 & 630.4 & 119.6 \\
\hline
\end{tabular}


a)

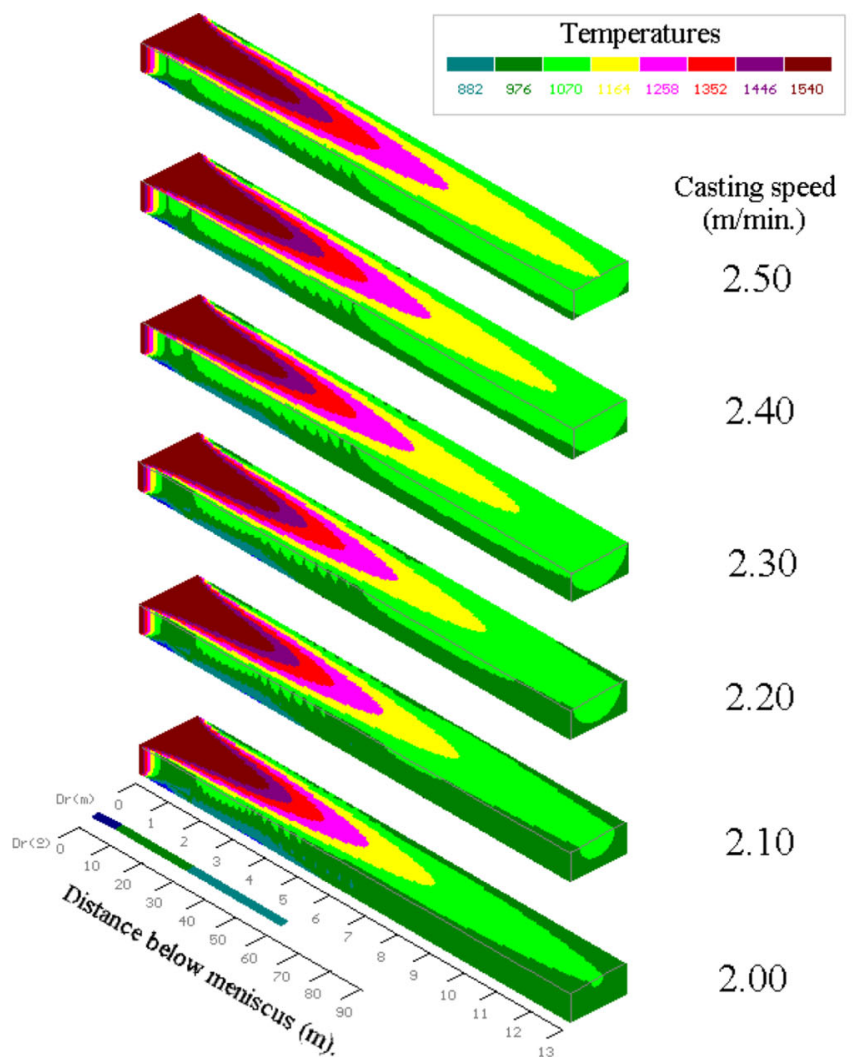

b)

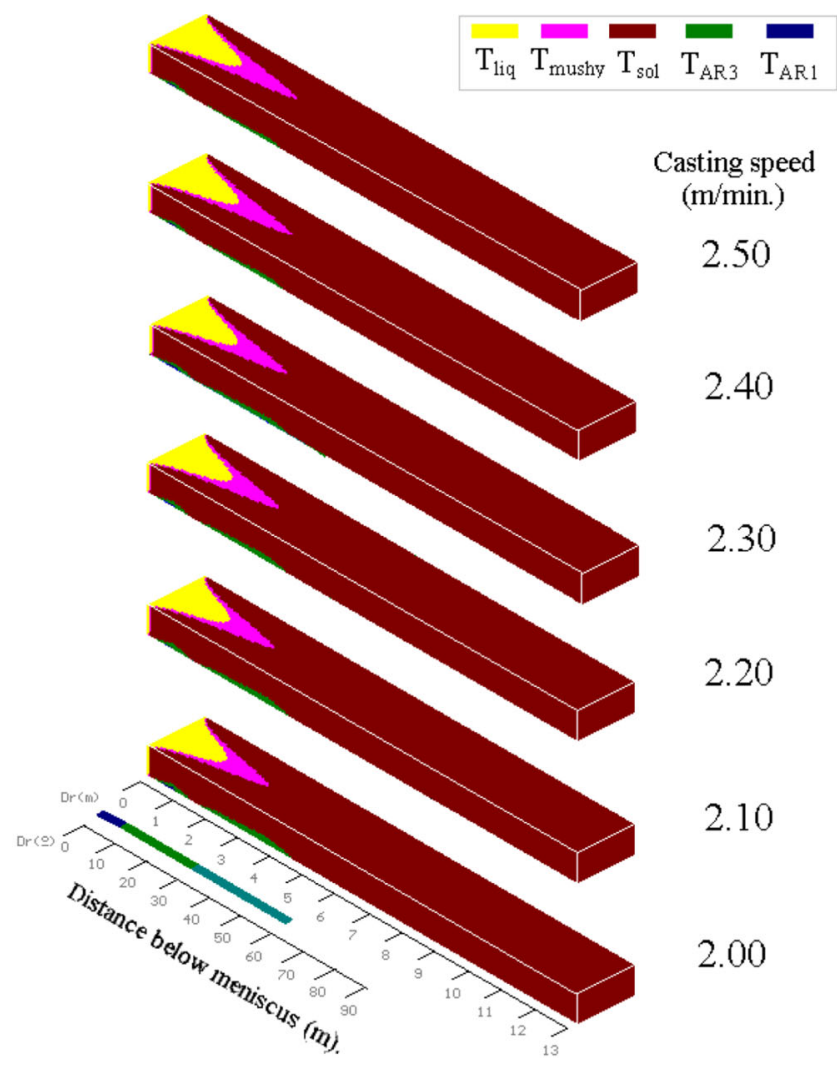

Fig. 17 Influence of the casting speed on the steel thermal behavior for a cast billet. a Temperature profile. b Solidification profile

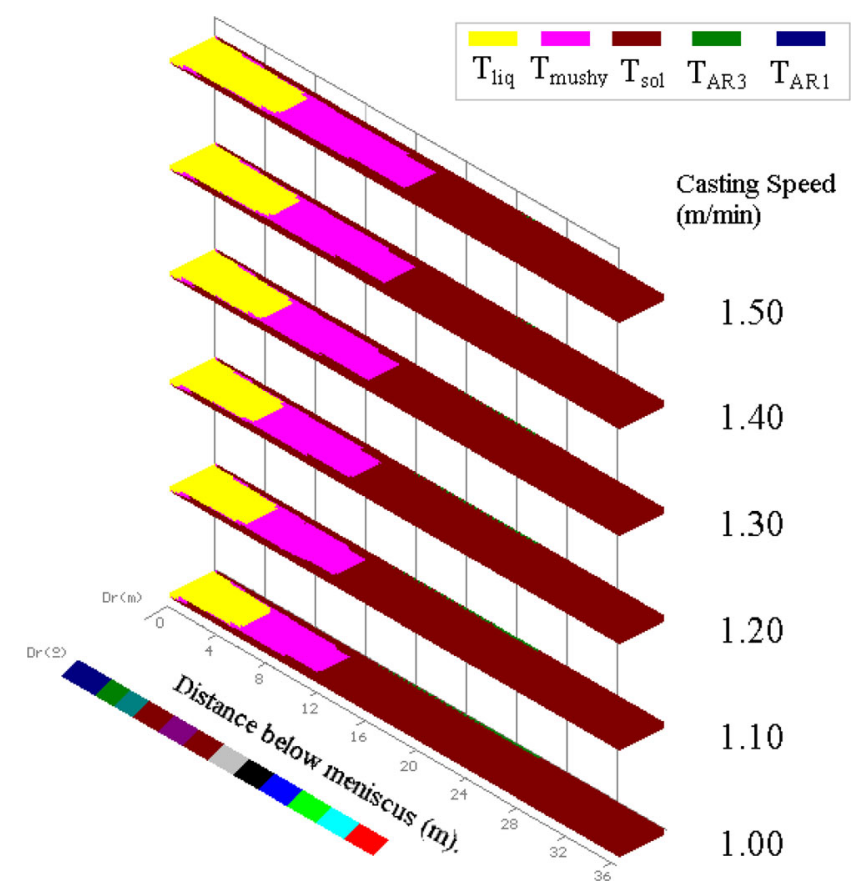

Fig. 18 Influence of the casting speed on the temperature profiles for a cast slab shooting angle $(\Omega)$ and the sprays are referred to the casting direction (the narrow faces: left and right). The graphs shown in Fig. 16 are only for the surface temperature using a casting speed $(1.00 \mathrm{~m} / \mathrm{min})$, and a comparison between broad and narrow faces is performed to note that the narrow surfaces remain always cooler than broad surfaces. The scale on the horizontal axis shows that this simulation was made for the entire CCM.

The simulator developed solves a 2D model for the steel volume. As a result, only one control volume is declared and used during the calculation of the steel thermal behavior. The interaction between other steel volumes, along the casting direction, is ignored because its contribution is consider as minor when in comparison with heat removal on billet lateral surfaces. Nevertheless, 3D profiles can be created using the temperature values at every moment $\left(T_{\mathrm{I}, \mathrm{J}}^{\mathrm{t}}\right)$ as is shown in Figs. 17 and 18. These profiles are built dynamically during simulation, taking and displaying the actual and latest values before these are updated. Moreover, the use of 3D models for solving heat removal is not advisable due to longer computing times and the need of huge amounts of computer memory and data space for declaring each new array. Moreover, the final temperature values calculated from $3 \mathrm{D}$ model are so similar with those obtained with the $2 \mathrm{D}$ model (only $5.25{ }^{\circ} \mathrm{C}$ 
Table 8 Comparison between temperatures calculated computationally and real lectures from CCM for case 1

\begin{tabular}{|c|c|c|c|c|c|c|}
\hline Segment & Between sprays & $\begin{array}{l}\text { Temperature max } \\
\left({ }^{\circ} \mathrm{C}\right)\end{array}$ & $\begin{array}{l}\text { Temperaturemin } \\
\left({ }^{\circ} \mathrm{C}\right)\end{array}$ & $\begin{array}{l}\text { Temperature average } \\
\left({ }^{\circ} \mathrm{C}\right)\end{array}$ & $\begin{array}{l}\text { Temperature simulated } \\
\left({ }^{\circ} \mathrm{C}\right)\end{array}$ & Error $\left({ }^{\circ} \mathrm{C}\right)$ \\
\hline 1 & \multicolumn{6}{|c|}{ This segment is only one single spray and it was un-accessible due to that it is the first segment below the mold. } \\
\hline \multirow[t]{2}{*}{2} & $7-8$ & 925 & 900 & 912.5 & 905 & 7.5 \\
\hline & $8-9$ & 917 & 895 & 906 & 910 & 4 \\
\hline \multirow[t]{3}{*}{3} & $4-5$ & 899 & 870 & 884.5 & 889 & 4.5 \\
\hline & $5-6$ & 895 & 865 & 880 & 882 & 2 \\
\hline & $6-7$ & 865 & 852 & 858.5 & 862 & 3.5 \\
\hline \multirow[t]{3}{*}{4} & $4-5$ & 860 & 849 & 854.5 & 858 & 3.5 \\
\hline & $5-6$ & 858 & 847 & 852.5 & 856 & 3.5 \\
\hline & $6-7$ & 855 & 845 & 850 & 854 & 4 \\
\hline \multirow[t]{4}{*}{ Distance in front the SCS } & 4 & 1005 & 999 & 1002 & 1000 & 2 \\
\hline & 5 & 995 & 991 & 993 & 995 & 2 \\
\hline & 6 & 985 & 980 & 982.5 & 983 & 0.5 \\
\hline & 7 & 978 & 974 & 976 & 977 & 1 \\
\hline
\end{tabular}

maximum variation in a temperature scale of $1500{ }^{\circ} \mathrm{C}$ is only a $0.35 \%)$. Thus, the computational efforts are not absolutely required. This difference was obtained after a heat removal calculation of a squared steel billet form $(114 \times 114 \mathrm{~mm})$, using a squared mesh with $100 \times 100$ nodes which was cast in a CCM at $2.25 \mathrm{~m} / \mathrm{min}$. This difference was calculated with the average temperature on all the used nodes at the end of the running just below the cutter flame. In other words, $5.25^{\circ} \mathrm{C}$ is the maximum difference between $2 \mathrm{D}$ and $3 \mathrm{D}$ models on every node of the frontal steel billet view. The averaged error between $2 \mathrm{D}$ and $3 \mathrm{D}$ model was $3.75^{\circ} \mathrm{C}$ for the three cases simulated on this work.

Figures 17 and 18 show the influence of the casting speed on heat removal. It is possible to see that for slow casting speeds, heat removal is more intense, because the control volume remains longer times inside the mold and under the sprayed areas of the SCS. Hence, the probability of surface reheating is reduced. The billet simulated in these figures has $125 \times 125 \mathrm{~mm}$. A squared mesh with identical elements $(100 \times 100)$ was used for discretization of the billet. Times between 245 and $325 \mathrm{~s}$ are required for the simulation along the entire CCM; thus, it can be consider as a very quick response. Figure $17 \mathrm{a}, \mathrm{b}$ shows the temperature and 3D solidification profiles calculated for the entire run in the CCM for case 3 . The profiles are showing the cast section with an internal cut to appreciate the thermal behavior inside the core; scales were adapted for a better view and flat un-curved display was also preferred. Here, the increment on surface reheating can also be appreciated as a function of the casting speed. In contrast, the solidification front is delayed as the casting speed is increased.

The solidification profiles for a slab, shown in Fig. 18, are indeed different to those for billets, due to the geometrical form of the cast section (rectangular and larger). Here, a large liquid steel pool remains for a long time inside the slab core. There is a final solidification time when a flat liquid front becomes to mushy state and other when mushy becomes to solid. Slabs are cast slowly in comparison with billets. The slab size simulated was a rectangular section $(200 \times 1600$ $\mathrm{mm})$. A mesh with rectangular elements was used for

Table 9 Comparison between temperatures calculated computationally and real lectures from CCM for case 2

\begin{tabular}{|c|c|c|c|c|c|c|}
\hline Segment & Between sprays & $\begin{array}{l}\text { Temperature max } \\
\left({ }^{\circ} \mathrm{C}\right)\end{array}$ & $\begin{array}{l}\text { Temperature min } \\
\left({ }^{\circ} \mathrm{C}\right)\end{array}$ & $\begin{array}{l}\text { Temperature average } \\
\left({ }^{\circ} \mathrm{C}\right)\end{array}$ & $\begin{array}{l}\text { Temperature simulated } \\
\left({ }^{\circ} \mathrm{C}\right)\end{array}$ & Error $\left({ }^{\circ} \mathrm{C}\right)$ \\
\hline \multirow[t]{2}{*}{1} & $5-6$ & 950 & 920 & 935 & 932 & 3 \\
\hline & $6-7$ & 945 & 917 & 931 & 930 & 1 \\
\hline \multirow[t]{2}{*}{2} & $5-6$ & 870 & 850 & 860 & 856 & 4 \\
\hline & $6-7$ & 860 & 850 & 855 & 853 & 2 \\
\hline \multirow[t]{4}{*}{ Distance in front the SCS } & 1 & 970 & 950 & 960 & 957 & 3 \\
\hline & 2 & 995 & 970 & 982.5 & 980 & 2.5 \\
\hline & 2 & 980 & 970 & 975 & 978 & 3.0 \\
\hline & 4 & 970 & 965 & 967.5 & 970 & 2.5 \\
\hline
\end{tabular}


Table 10 Comparison between temperatures calculated computationally and real lectures from CCM case 3

\begin{tabular}{|c|c|c|c|c|c|c|}
\hline Segment & Between sprays & $\begin{array}{l}\text { Temperature max } \\
\left({ }^{\circ} \mathrm{C}\right)\end{array}$ & $\begin{array}{l}\text { Temperature min } \\
\left({ }^{\circ} \mathrm{C}\right)\end{array}$ & $\begin{array}{l}\text { Temperature average } \\
\left({ }^{\circ} \mathrm{C}\right)\end{array}$ & $\begin{array}{l}\text { Temperature simulated } \\
\left({ }^{\circ} \mathrm{C}\right)\end{array}$ & Error $\left({ }^{\circ} \mathrm{C}\right)$ \\
\hline \multirow[t]{2}{*}{1} & $5-6$ & 825 & 817 & 821 & 820 & 1 \\
\hline & $6-7$ & 831 & 815 & 823 & 819 & 4 \\
\hline \multirow[t]{2}{*}{2} & $2-3$ & 835 & 820 & 827.5 & 823 & 4.5 \\
\hline & $3-4$ & 830 & 815 & 822.5 & 820 & 2.5 \\
\hline \multirow[t]{3}{*}{3} & $4-5$ & 760 & 740 & 750 & 746 & 4 \\
\hline & $5-6$ & 755 & 740 & 747.5 & 744 & 3.5 \\
\hline & $6-7$ & 750 & 735 & 742.5 & 742 & 0.5 \\
\hline \multirow[t]{4}{*}{ Distance in front the SCS } & 1 & 840 & 820 & 830 & 825 & 5 \\
\hline & 2 & 830 & 820 & 825 & 822 & 3 \\
\hline & 2 & 825 & 820 & 822.5 & 821 & 1.5 \\
\hline & 4 & 825 & 815 & 817.5 & 819 & 1.5 \\
\hline
\end{tabular}

discretization it. The used mesh includes $(50 \times 500)$ nonsquared nodes. Here, the values of the discretization elements $\Delta x$ and $\Delta y$ are not equal due to the slab narrow and wide sides. Although Eqs. (2) to (7) can be solved independently to obtain an appropriate step time $(\Delta t)$ for slabs, the use of a squared mesh where $\Delta x=\Delta y$ is desirable.

A mesh with 10,000 nodes provides a very good approach for the steel thermal behavior for a small size squared billet. In the other hand, the mesh with 25,000 nodes provides an acceptable approach for slabs; nevertheless, the use of a finer mesh is recommended to obtain better approached results for slab analysis cases (Tables 8, 9, and 10).

a)

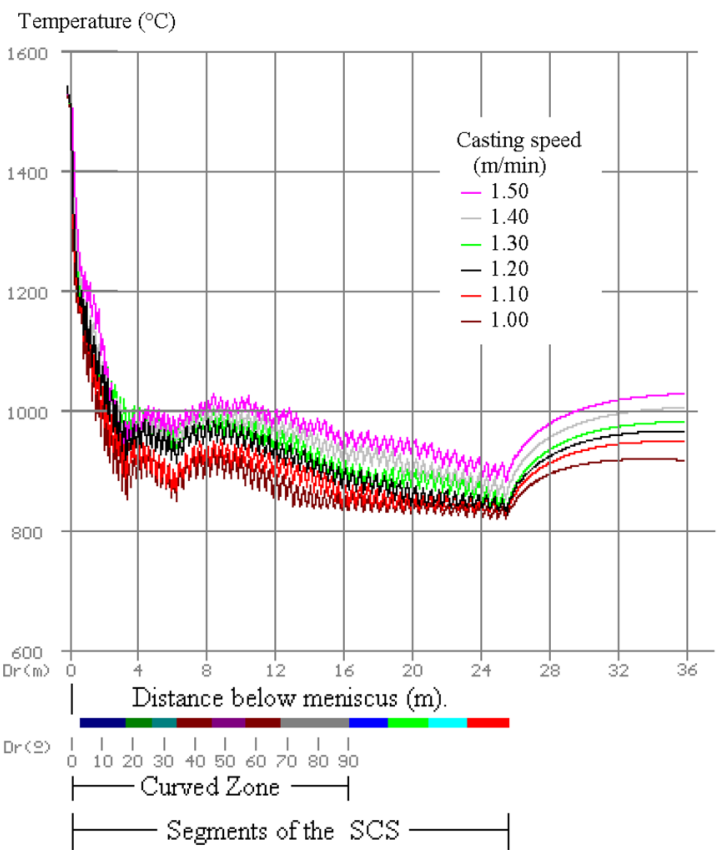

Figure 19a, $\mathrm{b}$ shows the steel thermal behavior for a slab on the narrow and broad faces, respectively. Here, the influence of the casting speed is evident. Narrow faces remain always cooler than broad ones due to the fact that heat removal is applied on a small surface. These graphs can be used to identify possible reheating under certain heat removal conditions if the surface temperature is increased at the end of the mold. Here, fluctuations on the narrow faces due to quenching and reheating in SCS are greater than those in the broad faces. The 11 sprays in the first segment of SCS efficiently quench the narrow faces although a light reheating occurs in the broad faces.

b)

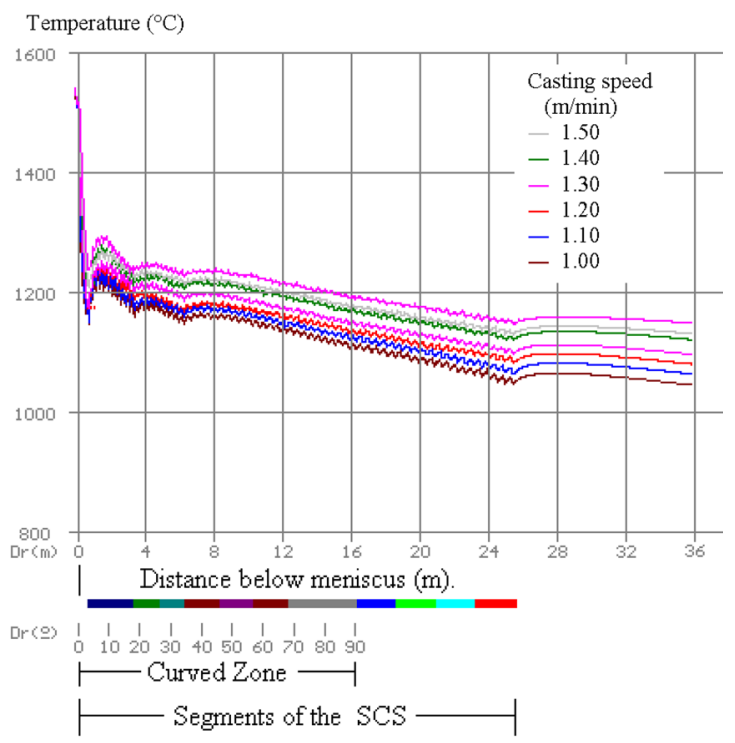

Fig. 19 Influence of the casting speed on the surface temperature for a slab. a Narrow faces. b Broad faces 


\section{Conclusions}

A novel computer simulator to analyze heat removal during steel continuous casting was developed. The computational algorithms developed are efficient and helpful and provide adequate and logical tools for users and designers.

The nested loops and the inclusion of routines provide the system with fast response tools.

A simulation using a mesh with $100 \times 100$ nodes for a squared billet section using a CCM $25 \mathrm{~m}$ total length delays $3 \mathrm{~min}$ due to many unnecessary operations has been performed; thus, the algorithm can be consider as efficient.

The graphical routines are a powerful tool for displaying results.

Computer simulations are very important to predict industrial parameters, and computational tools for displaying results can provide different points of view.

According to the performed simulations, heat removal conditions used in industrial trials are appropriate to guarantee safety conditions. However, faster casting speeds are desirable to increase production on strands, and calculations about the steel thermal behavior must be performed. In the same way, simulations must be done for different billet sizes and considering every caster conditions.

The algorithm and computational tools developed allow obtaining a quick response about the steel thermal behavior with a minor quantity of computational resources; moreover, these tools and algorithms can also be used for billets and slabs.

The nodes used to discretize the broad faces of the slabs must be increment proportionally to create finer meshes and to warrant a good approach.

According to the simulations done in the present work, the continuous casting speed can be increased using the casting conditions defined in order to increment the production and reduce the production time.

The quench over the broad face on the slabs is critical due to surface reheating that is more intense than in narrow faces.

The simulation techniques used can generate a 3D view of the steel sections without the use of huge memory resources; furthermore, this option can be used to show the influence of the casting speed on the steel thermal behavior.

Slabs require more intense heat removal conditions due to bigger dimensions; moreover, slabs also are more delicate cares due to the big volume of unsolidified steel inside the core.

Acknowledgments The present authors express their gratitude to Consejo Nacional de Ciencia y Tecnología (CONACyT). We also wish to express our gratitude to our affiliations Universidad Autónoma Metropolitana Unidad Azcapotzalco (UAM-A) and Instituto Tecnológico Autónomo de Mexico (ITAM) with special mention to Asociación Mexicana de Cultura for the financial and technical support.

Open Access This article is distributed under the terms of the Creative Commons Attribution 4.0 International License (http:// creativecommons.org/licenses/by/4.0/), which permits unrestricted use, distribution, and reproduction in any medium, provided you give appropriate credit to the original author(s) and the source, provide a link to the Creative Commons license, and indicate if changes were made.

\section{References}

1. Brimacombe JK (1976) Can Metall Q 15:163

2. Choudhary SK, Mazumdar D, Ghosh A (1993) Mathematical modelling of heat transfer phenomena in continuous casting of steel. ISIJ Int 33:764-774. doi:10.2355/isijinternational.33.764

3. Choudhary SK, Mazumdar D (1994) Mathematical modelling of transport phenomena in continuous casting of steel. ISIJ Int 34: 584-592. doi:10.2355/isijinternational.34.584

4. Choudhary SK, Mazumdar D (1995) Mathematical modelling of fluid flow, heat transfer and solidification phenomena in continuous casting of steel. Steel Research 66:199-205. doi:10.1002/srin. 199501112

5. Geiger GH (1987) Transport phenomena in metallurgy. Addison Wesley Publishing, p 285-291

6. Lait J, Brimacombe JK, Weinberg F (1974) Ironmak Steelmak 2:90

7. Li BQ (1997) Numerical simulation of flow and temperature evolution during the initial phase of steady-state solidification. J Mater Process Technol 71:402. doi:10.1016/S0924-0136(97)00105-2

8. Louhenkilpi S, Laitinen E, Nienminen R (1993) Real-time simulation of heat transfer in continuous casting. Metall Trans B 24(4): 685-693. doi:10.1007/BF02673184

9. Amin MR, Majan A (2006) Modeling of turbulent heat transfer during the solidification process of continuous castings. J Mater Process Technol 174:155-166. doi:10.1016/j.jmatprotec.2005.11. 035

10. Shi Z, Guo ZX (2004) Numerical heat transfer modelling for wire casting. Mater Sci Eng A 365:311-317. doi:10.1016/j.msea.2003. 09.041

11. Thomas BG, Samarasekera IV, Brimacombe JK (1984) Comparison of numerical modeling techniques for complex, twodimensional, transient heat-conduction problems. Metall Trans B 15:307-318. doi:10.1007/BF02667334

12. Thomas BG, Samarasekera IV, Brimacombe JK (1987) Mathematical model of the thermal processing of steel ingots: part II. Stress model. Metall Trans B 18:119. doi:10.1007/BF02658438

13. Blase TA, Guo ZX, Shi Z, Long K, Hopkins WG (2004) A 3D conjugate heat transfer model for continuous wire casting. Mater Sci Eng A-Struct 365:318-324. doi:10.1016/j.msea.2003.09.042

14. (1978) Physical constants of some commercial steels at elevated temperatures. B.I.R.S.A. London, Ed. Butterworths, p 1-38

15. Ramirez-Lopez A et al (2010) Simulation of the heat transfer in steel billets during continuous casting. Int J Miner Metall Mater 17(4):403-416. doi:10.1007/s12613-010-0333-5

16. Ramirez-Lopez A et al (2010) Simulation factors of the steel continuous casting. Int J Miner Metall Mater 17(3):267-275. doi:10. 1007/s12613-010-0304-X

17. Savage J, Pritchard WH (1954) J Iron Steel Inst 178:269

18. Ramirez-Lopez A et al (2010) Computational algorithms to simulate the steel continuous casting. Int J Miner Metall Mater 17(5): 596-607. doi:10.1007/s12613-010-0362-0 
19. Dauby PH, Assar MB, Lawson GD (2001) PIV amd MFC measurements in a continuous caster mould. New tools to penetrate the caster black box. La Revue de Metallurgie - CIT 98(4):353-366

20. Thomas BG (2003) Chapter 14. Fluid flow in the mold. In: Cramb A (ed) Making, shaping and treating of steel: continuous casting, vol vol. 5. AISE Steel Foundation, Pittsburgh, pp 14.1-14.41

21. Thomas BG (2006) Modeling of continuous-casting defects related to mold fluid flow. Iron Steel Technol (AIST Trans) 3(7):128-143

22. Louhenkilpi S (1995) Acta Polytech Scand Chem Technol Ser No. 230

23. Oliveira MJ, Malheiros LF, Ribeiro CAS (1999) Evaluation of the heat of solidification of cast irons from continuous cooling curves. J Mater Process Technol 92-93:25-30. doi:10.1016/S0924-0136(99) 00181-8

24. Das SK (2001) Evaluation of solid-liquid interface profile during continuous casting by a spline based formalism. Bull Mater Sci 24: 373. doi:10.1007/BF02708633

25. Fachinotti VD, Cardona A (2003) Constitutive models of steel under continuous casting conditions. J Mater Process Technol 135: 30-43. doi:10.1016/S0924-0136(02)00955-X

26. Janik M, Dyja H (2004) Modelling of three-dimensional temperature field inside the mould during continuous casting of steel. J Mater Process Technol 157:177-182. doi:10.1016/j.jmatprotec. 2004.09.026

27. Kulkarni MS, Babu AS (2005) Managing quality in continuous casting process using product quality model and simulated annealing. J Mater Process Technol 166:294-306. doi:10.1016/j. jmatprotec.2004.09.073
28. Hibbins SG (1982) Characterization of heat transfer in the secondary cooling system of a continuous slab caster. Ph.D. Thesis, University of British Columbia, p 20-50, 65-82, 110-119, 125-150

29. Emling WH, Waugaman TA, Feldbauer SL, Cramb AW (1994) Subsurface mold slag entrainment in ultra-low carbon steels. In: Steelmaking Conf. Proc., Vol. 77, ISS, Warrendale, PA, (Chicago, IL), p 371-379

30. Zhao B, Thomas BG, Vanka SP, O’Malley RJ (2005) Transient fluid flow and superheat transport in continuous casting of steel slabs. Metall Mater Trans B 36B(12 (December)):801-823. doi: 10.1007/s11663-005-0083-3

31. Yuan Q, Zhao B, Vanka SP, Thomas BG (2004, (New Orleans, LA, Sept. 26-29), TMS, Warrendale, PA) Study of computational issues in simulation of transient flow in continuous casting. Mater Sci Technol II:333-343

32. (1993) Heat Transfer Problem Solvers, Research \& Education Association Piscataway New Jersey, p 17-81, 385-410, 424-461, 505-520

33. Crank J, Nicholson P (1947). In: Proceedings of the Cambridge Philosophical Society 43, p 50

34. Gerald CF, Wheatley PO (1994) Applied numerical analysis. Addison Wesley Publishing Company, U.S.A., pp 616-658

35. Wicks CE, Wilson RE, Welty JR (1984) Fundamentals of momentum, heat and mass transfer. John Wiley \& Sons, U.S.A., p 269

36. Thomas BG, O'Malley R, Shi T, Meng Y, Creech D, Stone D (2000) Validation of fluid flow and solidification simulation of a continuous thin slab caster. In: Modeling of casting, welding, and advanced solidification processes, Vol. IX, Shaker Verlag GmbH, Aachen, Germany, (Aachen, Germany, August 20-25, 2000), p 769-776 